\title{
QBO modulation of the semiannual oscillation in MAECHAM5 and HAMMONIA
}

\author{
C. Peña-Ortiz, ${ }^{1}$ H. Schmidt, ${ }^{2}$ M. A. Giorgetta, ${ }^{2}$ and M. Keller ${ }^{3}$ \\ Received 19 January 2010; revised 15 July 2010; accepted 27 July 2010; published 4 November 2010.
}

[1] The quasi-biennial oscillation (QBO) signature in the equatorial upper stratosphere and mesosphere is analyzed from MAECHAM5 and HAMMONIA general circulation models. Our results show that this region is significantly influenced by the stratospheric QBO. In the upper stratosphere the QBO modulates the altitude of maximum descent of the stratospheric semiannual oscillation (SSAO) westerly phases. Our results also suggest that the QBO modulates the altitude of maximum descent and also the strength of the SSAO easterly phase. We explore the role of large-scale and small-scale waves and also momentum advection in the forcing of the QBO signature in the SSAO domain. The results show how the vertical propagation of the QBO signature to the middle and upper mesosphere depends on the vertical phase structure of the SAO and consequently on the seasonal cycle. During the solstices when MSAO westerlies prevail in the middle and upper mesosphere no QBO signature can be detected above the stratopause region. However, during the equinoxes, when MSAO easterlies dominate in the middle and upper mesosphere, the QBO signature extends throughout the mesosphere and low thermosphere. The QBO directly modulates MSAO easterlies by modifying the altitude at which they are generated in the upper mesosphere. A QBO signature is also detected on the MSAO westerly phase occurring in the mesopause region during the equinoxes.

Citation: Peña-Ortiz, C., H. Schmidt, M. A. Giorgetta, and M. Keller (2010), QBO modulation of the semiannual oscillation in MAECHAM5 and HAMMONIA, J. Geophys. Res., 115, D21106, doi:10.1029/2010JD013898.

\section{Introduction}

[2] Large-scale dynamics of the equatorial middle atmosphere are dominated by long-period oscillations of zonal winds with quasi-biennial period in the stratosphere and semiannual period at the stratopause and in the mesosphere. Earlier studies have indicated that the mesospheric oscillations are strongly influenced by the stratosphere. The exact mechanisms are, however, not fully understood. This modeling study is intended to further improve this understanding.

[3] The quasi-biennial oscillation (QBO) of alternating easterly and westerly winds is the dominant feature of the tropical stratosphere between 5 and $100 \mathrm{hPa}$ [Pascoe et al., 2005]. The QBO amplitude is approximately Gaussian about the equator with a $12^{\circ}$ half width. The zonal winds between 5 and $40 \mathrm{hPa}$ reach maxima between 20 and $35 \mathrm{~m} / \mathrm{s}$, with stronger easterly than westerly winds, and decrease rapidly below $50 \mathrm{hPa}$. Above $5 \mathrm{hPa}$ the variability is dominated by the semiannual oscillation (SAO). Pascoe et al. [2005] observed in the ERA40 reanalysis that when the

\footnotetext{
${ }^{1}$ Departamento de Sistemas Químicos, Físicos y Naturales, Universidad Pablo de Olavide, Sevilla, Spain.

${ }^{2}$ Max Planck Institute for Meteorology, Hamburg, Germany.

${ }^{3}$ Department of Physics, University of Toronto, Toronto, Ontario, Canada.

Copyright 2010 by the American Geophysical Union. 0148-0227/10/2010JD013898
}

annual cycle and the SAO are removed, the QBO signal can be seen to extend as high as $1 \mathrm{hPa}$ although its amplitude is reduced to about $5-10 \mathrm{~m} / \mathrm{s}$.

[4] Reed [1962] first documented the existence of an SAO in zonal winds in the tropical upper stratosphere. Hirota [1978] used rocket observations to show that the SAO in fact consist of two oscillations with amplitude maxima near the stratopause and mesopause, defined as the stratospheric SAO (SSAO) and mesospheric SAO (MSAO), and an amplitude minimum near $65 \mathrm{~km}$. As in the QBO case, SAO signals are not limited to zonal winds but can be identified also in vertical winds, temperature, and trace gas concentrations.

[5] Delisi and Dunkerton [1988] first noted the seasonal asymmetry of the SSAO. The first cycle of the SSAO, beginning with easterlies in the Northern Hemisphere winter, is usually stronger than the second cycle beginning with easterlies in the Southern Hemisphere winter. Maximum easterlies lie in the range -20 to $-60 \mathrm{~m} / \mathrm{s}$, while westerlies reach between 20 and $40 \mathrm{~m} / \mathrm{s}$. The easterly phase of the SSAO is believed to be mainly driven by meridional advection of easterly momentum tying the entire SAO to the seasonal cycle and determining its semiannual period. Delisi and Dunkerton [1988] attributed the seasonal asymmetry to stronger dynamical forcing in the northern winter producing stronger easterlies and setting the stage for a strong westerly phase immediately following the strong easterly phase. The MSAO is out of phase with the SSAO. Garcia et al. [1997] 
used MF radar observations for the years 1990-1995 and satellite measurements from the High Resolution Doppler Imager (HRDI) on the Upper Atmosphere Research Satellite (UARS) for the years 1992-1995 to show that the MSAO also exhibits a seasonal asymmetry which is most evident at $80-85 \mathrm{~km}$. Easterlies in the first cycle of the oscillation (April) were observed to be considerably stronger than in the second cycle (October). The peak values are $-50 \mathrm{~m} / \mathrm{s}$ in the first cycle versus $-40 \mathrm{~m} / \mathrm{s}$ in the second according to HRDI data and $-40 \mathrm{~m} / \mathrm{s}$ versus $-20 \mathrm{~m} / \mathrm{s}$ according to radar. The westerly regime shows little seasonal variability with a mean value of around $15 \mathrm{~m} / \mathrm{s}$.

[6] Previous studies [Garcia et al., 1997; Dunkerton and Delisi, 1997] found in rocketsonde data covering the period 1961 to 1991 a modulation of the SSAO and MSAO by the QBO. Their studies revealed that SSAO westerlies descend farther when QBO westerlies wane in the low stratosphere. So it is the altitude of maximum descent, and not the strength, of the SSAO westerlies that is modulated by the QBO. They did not observe any variation of the SSAO easterly phase associated with QBO. Garcia et al. [1997] used HRDI and MF radar data to show that the easterly phase of the MSAO is stronger when deep QBO westerlies are present in the stratosphere than during the QBO easterly phase. No QBO modulation of the MSAO westerlies was found.

[7] The accepted explanation for the QBO modulation of the SSAO is that the waves driving the SAO are filtered as they traverse the QBO winds in the stratosphere. Garcia et al. [1997] particularly emphasized the importance of small-scale gravity waves, particularly the seasonal variation of their sources and transmission. Garcia and Sassi [1999] used an equatorial beta-plane model to show that the QBO filtering of inertia-gravity waves might be also important in the QBO modulation of the MSAO easterlies. Mayr et al. [1997] used another numerical model to show that the filtering of smallscale gravity waves could play a role in the QBO modulation of the MSAO easterly phase.

[8] The main difficulty for analyzing the QBO signature in the upper stratosphere and mesosphere is the important lack of data at this altitude. Data sets obtained from rocketsonde, radar and satellite observations are too short to offer a significant pattern of the QBO signature in the SAO domain. Results obtained with data from different sources are sometimes inconsistent. For example, the QBO modulation of the MSAO was observed in both satellite and radar data from 1992 to 1995 but no correlation was observed in the radar measurements during 1990-1991 [Garcia et al., 1997]. This makes it difficult to reliably confirm if the mesospheric QBO (MQBO) is linked to the stratospheric QBO.

[9] Atmospheric circulation models can play an important role in the study of the QBO signature in the upper stratosphere and mesosphere by providing data of higher spatial and temporal resolution and covering longer time periods than is available from observations. Previous studies by Mayr et al. [1997] and Garcia and Sassi [1999] used 2-D and equatorial beta-plane models, respectively. Here we use data from two related general circulation models that internally generate the QBO to provide a description of the QBO influence on zonal wind in the upper stratosphere and mesosphere. This study also seeks to analyze the relationship between MQBO and the QBO and to investigate the mechanism through which the QBO modulates the easterly and westerly phases of the SAO.

\section{Numerical Models}

[10] Data from two different but related general circulation models have been used in this study: from the MAECHAM5 model [Manzini et al., 2006], which is the middle atmosphere configuration of the ECHAM5 general circulation model [Roeckner et al., 2003, 2006] and from the Hamburg Model of the Neutral and Ionized Atmosphere (HAMMONIA) [Schmidt et al., 2006] which is an upward extension of MAECHAM5.

[11] The MAECHAM5 version used in this study resolves the atmosphere in 90 vertical levels from the surface to $0.01 \mathrm{hPa}(\sim 80 \mathrm{~km})$ altitude. In the stratosphere, the vertical resolution is approximately $700 \mathrm{~m}$ between the tropopause and $42 \mathrm{~km}$ height and less than $1 \mathrm{~km}$ up to the stratopause. This vertical resolution permits the simulation of the QBO based on resolved and parameterized wave mean-flow interaction [Giorgetta et al., 2002, 2006]. In MAECHAM5, the wave-mean flow interaction involves both the resolved dynamical effects including waves up to the truncation limit at wave number 42 , which is diagnosed as the divergence of the EP flux, and the parameterized effects of the interaction of the gravity waves with the resolved wind [Giorgetta et al., 2006]. Sea surface temperature (SST) and sea ice distribution are prescribed as lower boundary conditions following the monthly climatology of the period 1979-1996 (AMIP2 data set), thus excluding atmospheric responses to El Niño or La Niña SST signals. Natural external forcings by major volcanic eruptions or by 11 -year solar cycle variations of the irradiance are also neglected in the experiment.

[12] HAMMONIA is a general circulation and chemistry model based on MAECHAM5 but extended further upward into the thermosphere (with an upper lid at about $250 \mathrm{~km}$ ), and coupled to the MOZART3 chemistry scheme [Kinnison et al., 2007]. A detailed model description is given by Schmidt et al. [2006, 2010]. For this study the model has been run with a triangular truncation at wave number 31 (T31) and with 119 levels ranging from the surface to $1.7 \times$ $10^{-7} \mathrm{hPa}(\sim 250 \mathrm{~km})$. The momentum forcing caused by orographic and nonorographic gravity waves in HAMMONIA, as in MAECHAM5, is parameterized following the approaches by Lott and Miller [1997] and Hines [1997a, 1997b]. The parameter settings in the HAMMONIA simulations presented here are exactly the same used for the MAECHAM5 simulations [see also Schmidt et al., 2010]. This implies in particular a gravity wave source function that is constant in time, horizontally homogeneous, and azimuthally isotropic. In HAMMONIA, as well as for MAECHAM5, the launch level of the parameterized gravity waves is in the midtroposphere, at $671 \mathrm{hPa}$ and $535 \mathrm{hPa}$ for HAMMONIA and MAECHAM5, respectively. The vertical resolution is identical to that used in the 90-layer MAECHAM5 model up to about $0.1 \mathrm{hPa}$. The main differences between the two models in this altitude region are the interactive chemistry coupling in HAMMONIA and slightly different radiative schemes [see Schmidt et al., 2006]. So like MAECHAM5, HAMMONIA implicitly generates a QBO. The reason for using both models here is that due to high computational costs, so far, HAMMONIA has only been run at the relatively low spectral resolution of T31, 

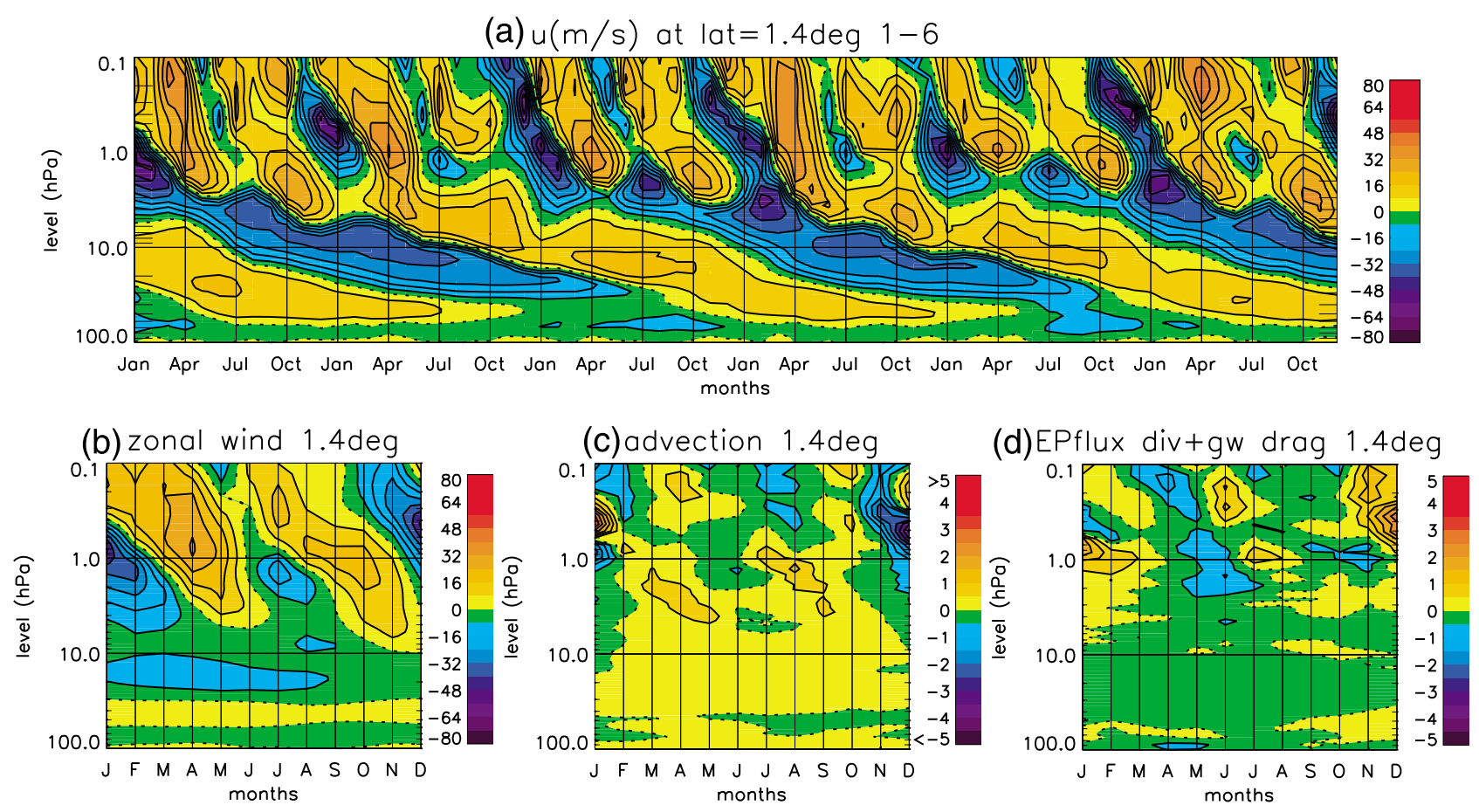

Figure 1. (a) Time-height section of the monthly mean zonal-mean zonal wind (m/s) for 6 years simulated with MAECHAM5 at $1.4^{\circ} \mathrm{N}$ from $100 \mathrm{hPa}$ to $0.1 \mathrm{hPa}$. (b) Monthly mean climatologies of the zonal-mean zonal wind at $1.4^{\circ} \mathrm{N}$ averaged over 30 years as simulated by MAECHAM5, (c) total advection of zonal momentum (meridional plus vertical advection) and (d) EP flux divergence plus gravity wave drag.

leading to a somewhat less realistic QBO than in MAECHAM5 (see below). On the other hand, owing to its high upper lid, only HAMMONIA offers the possibility to study the mesospheric SAO.

[13] For this study we have performed 30-year time slice simulations with both models forced with greenhouse gas concentrations typical for the 1990s and climatological AMIP2 sea surface temperatures and sea ice. We have analyzed zonal and monthly means of zonal wind, Eliassen Palm flux divergence and gravity wave drag. In the case of MAECHAM5, data from a subset of 59 model levels from 100 to $0.1 \mathrm{hPa}$ with a latitudinal resolution of approximately $2.8^{\circ}$ have been chosen; in the case of HAMMONIA, a subset of 80 model levels from 100 to $10^{-5} \mathrm{hPa}$ with a latitudinal resolution of approximately $3.7^{\circ}$. Further, we have used 3-hourly temperature series from HAMMONIA to produce wave spectra with the aim of investigating the characteristics of the waves involved in the QBO modulation of the MSAO.

[14] Both the QBO and SAO are internally generated by the two models. As has been shown in previous studies [Giorgetta et al., 2002, 2006; Calvo et al., 2007; Peña-Ortiz et al., 2008], the MAECHAM5 simulation of the QBO exhibits the typical properties of the observed QBO. Amplitudes of westerly and easterly phases, the period of the oscillation, the propagation characteristics of both phases and the differences in the latitudinal extent of both phases are realistically captured by MAECHAM5 [Giorgetta et al., 2002].

[15] Figure 1a shows the time-height section of the monthly mean zonal-mean zonal wind in MAECHAM5 at
1.4 $\mathrm{N}$ from $100 \mathrm{hPa}$ to $0.1 \mathrm{hPa}$ and for six arbitrarily chosen years. In the stratosphere, from $70 \mathrm{hPa}$ to $5 \mathrm{hPa}$ aproximately, the QBO dominates the interannual variability. Above $5 \mathrm{hPa}$, the SAO clearly appears as the dominant oscillation. The annual cycle of the zonal wind averaged over 30 years as simulated by MAECHAM5 is depicted in Figure 1b. Consistent with the observations [Delisi and Dunkerton, 1988] it shows a SSAO characterized by a first and stronger cycle beginning with stratopause easterlies in December and a second and weaker one beginning with easterlies in June. During the first cycle, maximum SSAO easterlies and westerlies reach on average around $-45 \mathrm{~m} / \mathrm{s}$ and $35 \mathrm{~m} / \mathrm{s}$, respectively, while during the second cycle they reach around $-20 \mathrm{~m} / \mathrm{s}$ and $20 \mathrm{~m} / \mathrm{s}$. The magnitude of both westerlies and easterlies of the strong and weak cycles lie in the range of previous observations [Delisi and Dunkerton, 1988; Garcia et al., 1997].

[16] Figures 1c and 1d depict the annual cycle of the zonal momentum forcing due to the total advection, as the sum of meridional and vertical advection, and to the wave-mean flow interaction process, as the sum of EP flux divergence and the parameterized gravity wave drag. Consistent with previous studies [Holton and Wehrbein, 1980; J. D. Mahlman and R. W. Sinclair, Recent results from the GFDL tropospherestratosphere-mesosphere general circulation model, paper presented at ICMUA Sessions and IUGG Symposium18, 17th IUGG General Assembly, Canberra, ACT, Australia, 1980], Figures 1c and 1d show that momentum advection is the main forcing of the SSAO easterlies of the strong cycle (December to February) reaching absolute values above 
$4.5 \mathrm{~m} / \mathrm{s} / \mathrm{d}$ in the stratopause region. However, results show that the contribution of the waves is also important. Previous studies considered the possibility that quasi-stationary planetary waves contribute to the forcing of the SSAO easterlies [Hamilton, 1986]. Here, the combined contribution of largescale and gravity waves produce easterly tendencies reaching $1 \mathrm{~m} / \mathrm{s} / \mathrm{d}$ in October-November at $1 \mathrm{hPa}$ contributing to the weakening of the SSAO westerly phase. Then, in JanuaryFebruary, waves partially compensate the forcing due to advection producing a westerly forcing slightly above $2.5 \mathrm{~m} / \mathrm{s} / \mathrm{d}$ in the stratopause region. The forcing due to both advection and waves strongly decrease below $1 \mathrm{hPa}$. On the contrary, waves play a more dominant role in the forcing of the SSAO easterly phase of the weak cycle (June-August) causing easterly tendencies between 0.5 and $1 \mathrm{~m} / \mathrm{s} / \mathrm{d}$ while easterly tendencies due to advection do not exceed $0.5 \mathrm{~m} / \mathrm{s} / \mathrm{d}$. It is possible that the simulated contribution of the waves-mean flow interaction process to the forcing of the SSAO easterly phase is overestimated and that for this reason SSAO easterlies show relatively strong downward propagation. However, the shortage of observational data from the upper stratosphere and mesosphere makes it impossible to assess whether the simulated role of the waves is realistic or not. It is believed that large-scale Kelvin waves and also small gravity waves are important for forcing the SSAO westerly phase [Hitchman and Leovy, 1988; Ray et al., 1998]. Figures 1c and $1 \mathrm{~d}$ show that both wave forcing and advection cause tendencies ranging between 0 to $1 \mathrm{~m} / \mathrm{s} / \mathrm{d}$ in the stratopause region.

[17] Figure 2a shows the time-height section of the monthly mean zonal wind at $1.85^{\circ} \mathrm{N}$ from six arbitrarily chosen years of the HAMMONIA simulation. The QBO simulated by HAMMONIA has characteristics very similar to the oscillation generated in MAECHAM5. The amplitude of the westerly and easterly phases is of the same magnitude and also the latitudinal and vertical extents of the signal are comparable. However, the QBO signature in HAMMONIA has an almost regular period of 2 years instead of the variable and on average longer QBO period that is observed and also simulated with MAECHAM5. In HAMMONIA the QBO is tied to the seasonal cycle in such a way that for each season the QBO will show a certain phase or its opposite but never the intermediate phases. MAECHAM5 experiments with different horizontal resolution (not presented here) have indicated that the simulated QBO period increases toward realistic values with increasing resolution. However, also the other differences between MAECHAM5 and HAMMONIA (e.g., interactive ozone chemistry) may have an influence on the simulated QBO period.

[18] Above $\sim 5 \mathrm{hPa}$ the zonal wind oscillates with the $\mathrm{SAO}$ that extends throughout the mesosphere. Figure $2 \mathrm{~b}$ shows the annual cycle of the zonal wind averaged over 30 years as simulated by HAMMONIA. It depicts prevailing westerlies at $0.1 \mathrm{hPa}(65 \mathrm{~km}$ approximately) from January to October. Consistent with previous observations [Delisi and Dunkerton, 1988], this layer separates two SAO amplitude maxima at upper and lower levels leading to two separated oscillations, the SSAO and the MSAO. However, easterlies uninterruptedly descend from the upper mesosphere to the stratopause during September-March leading to strong easterlies at $0.1 \mathrm{hPa}$ during November-January. This gives rise to a SAO that propagates downward from the mesopause to the stra- topause without decrease of amplitude. In comparison with observations [Garcia et al., 1997] HAMMONIA seems to overestimate the amplitude of the SAO easterlies in the middle mesosphere.

[19] In Figure 2b the simulated MSAO extends over a wide altitude range from $0.1 \mathrm{hPa}$ to $0.001 \mathrm{hPa}$ approximately, reaching the mesopause region and even the low thermosphere. A twofold structure can be distinguished with MSAO winds of opposite phases at different altitudes. During the equinoxes westerlies in the mesopause region overlie easterlies in the upper mesosphere and during the northern summer solstice mesopause easterlies overlie westerlies in the upper mesosphere. This is not observed during the northern winter solstice, when westerlies extend from $0.1 \mathrm{hPa}$ throughout the mesosphere and lower thermosphere.

[20] Figure $2 b$ shows a seasonal asymmetry in the SSAO with a strong cycle that begins with the easterly phase during the northern winter, when averaged easterlies reach absolute values above $50 \mathrm{~m} / \mathrm{s}$, and a weak cycle with easterlies with absolute values below $25 \mathrm{~m} / \mathrm{s}$ beginning during the southern winter. This asymmetry is much weaker in the SSAO westerlies that fluctuate between about 25 and $30 \mathrm{~m} / \mathrm{s}$. The simulated amplitude of the simulated SSAO easterlies and westerlies lie in the range of previous observations [Delisi and Dunkerton, 1988]. Below $0.01 \mathrm{hPa}, \mathrm{MSAO}$ easterlies show a seasonal asymmetry. However, contrary to previous observations [Garcia et al., 1997], these are stronger during the northern autumn. This should be considered as a result of the overestimation of the simulated MSAO easterlies between September and November. The MSAO westerly phase in HAMMONIA also show a seasonal asymmetry with stronger westerlies during the northern winter, when they lie above the strong SSAO easterlies. The seasonal variability of the MSAO westerly phases has not been confirmed by observations [Garcia et al., 1997].

[21] Figures $2 \mathrm{c}$ and $2 \mathrm{~d}$ are equivalent to Figures $1 \mathrm{c}$ and $1 \mathrm{~d}$ but for HAMMONIA. Concerning the forcing of the SSAO, momentum advection and wave forcing tendencies are similar to those observed for MAECHAM5. It must be emphasized that, as in MAECHAM5, advection plays a dominant role in the forcing of the strong easterly phase of the SSAO causing easterly tendencies reaching $4 \mathrm{~m} / \mathrm{s} / \mathrm{d}$ that are partially compensated by westerly tendencies below $3 \mathrm{~m} / \mathrm{s} / \mathrm{d}$ caused by the wave forcing. In the case of the forcing of the weak easterly phase both advection and wave forcing tendencies show anomalies below $0.5 \mathrm{~m} / \mathrm{s} / \mathrm{d}$. Less clear is the case of the MSAO forcing. As observed, the MSAO at around $0.01 \mathrm{hPa}$ is out of phase with the SSAO. This is explained by the selective wave filtering around the stratopause. And indeed, wave forcing terms are also opposite in phase between stratopause and upper mesosphere.

[22] Figure 3 shows the peak-to-peak amplitudes of the QBO and SAO as simulated in MAECHAM5 and in two versions of HAMMONIA, one with an internally generated QBO and another with no QBO signature. Only to produce this plot we have used a second model run with 67 (instead of 119) vertical levels ranging from the surface to $1.7 \times 10^{-7} \mathrm{hPa}$ $(\sim 250 \mathrm{~km})$ [Schmidt et al., 2006]. As a consequence of the lower vertical resolution, this model version does not simulate the QBO of equatorial stratospheric winds. SAO and QBO amplitudes have been computed following the method of Baldwin and Gray [2005]. Spectral filters with band pass 
(a) $u(\mathrm{~m} / \mathrm{s})$ at lat $=1.85$ deg. $1-6$

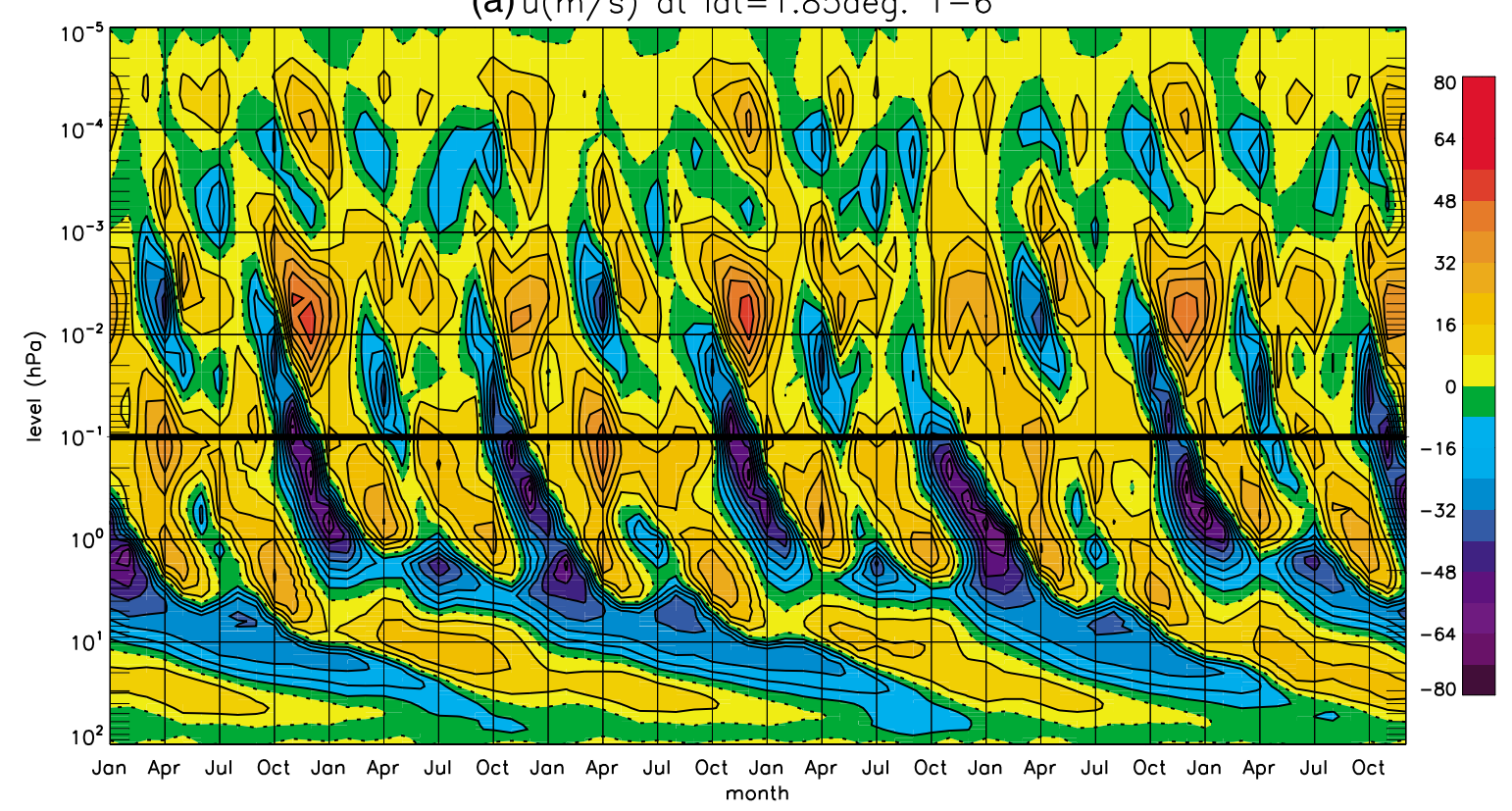

(b) zonal wind $1.85 \mathrm{deg}$

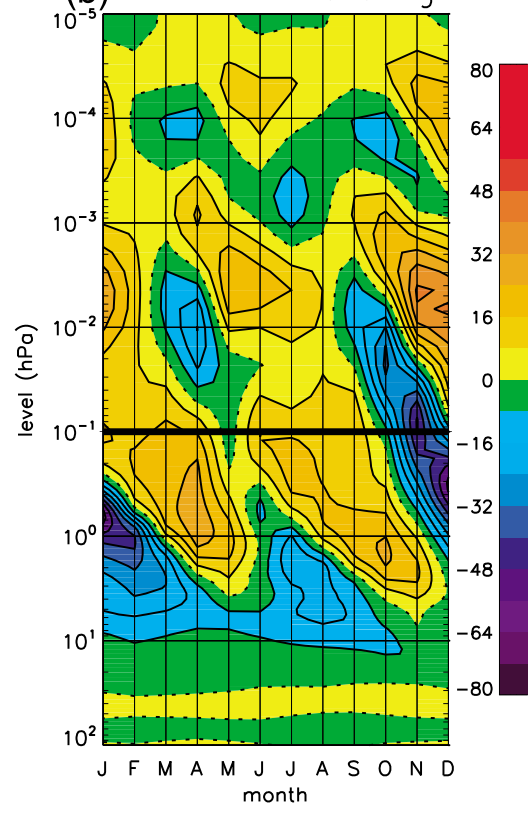

(c) advection $1.85 \mathrm{deg}$

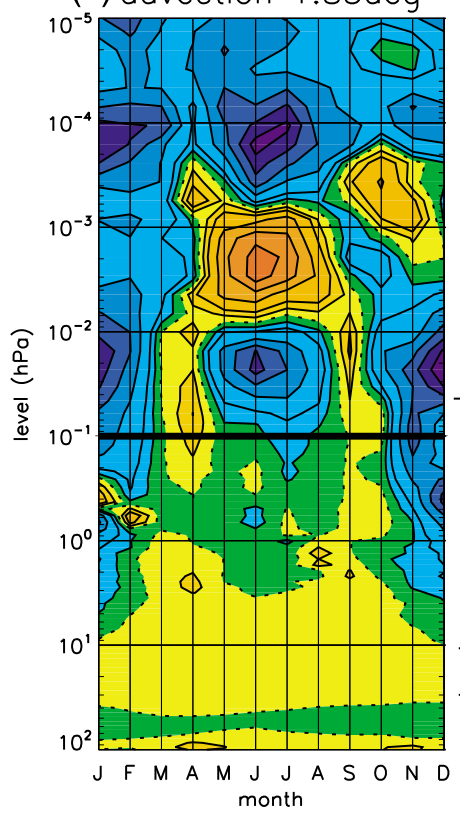

(d) EPflux div+gw drag $1.85 \mathrm{deg}$

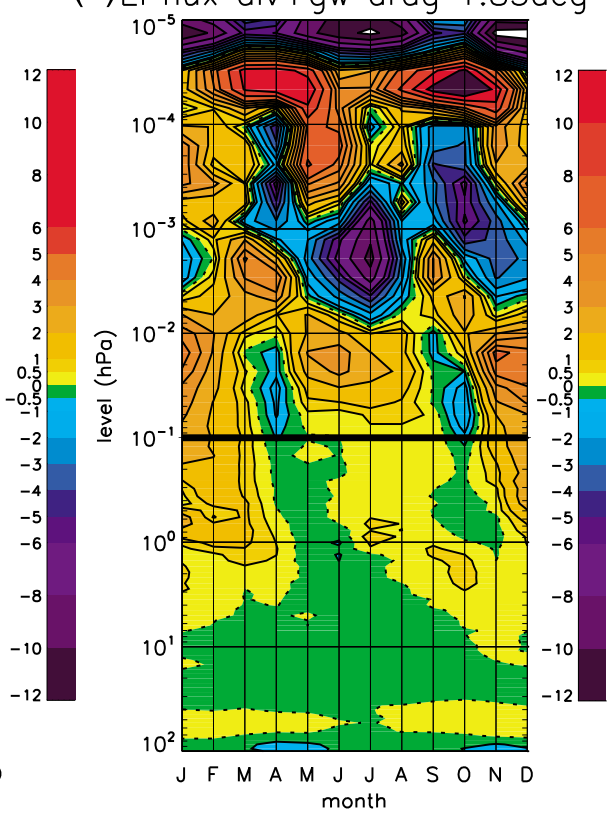

Figure 2. (a)Time-height section of the monthly mean zonal wind $(\mathrm{m} / \mathrm{s})$ for 6 years simulated with HAMMONIA at $1.85^{\circ} \mathrm{N}$ from 100 to $10^{-5} \mathrm{hPa}$. (b) Monthly mean climatologies of the zonal-mean zonal wind at $1.85^{\circ} \mathrm{N}$ averaged over 30 years as simulated by HAMMONIA, (c) total advection of zonal momentum (meridional plus vertical advection) and (d) EP flux divergence plus gravity waves drag.

periods of 20-40 months and 20-28 months have been used to isolate the QBO signal in MAECHAM5 and HAMMONIA, respectively.

[23] Results shown in Figure 3 (left) reveal that the HAMMONIA simulation with no stratospheric QBO does not exhibit any QBO signature either in the mesosphere or in the lower thermosphere. This result strongly supports the idea that the mesospheric QBO is linked to the QBO of the equatorial stratospheric winds. Therefore it is expected that models that do not have a QBO will not be able to simulate QBO variability in the mesosphere and lower thermosphere.

[24] Figure 3 (left) suggest a close agreement in the amplitude of the QBO as simulated in MAECHAM5 and HAMMONIA that shows a maximum around $50 \mathrm{~m} / \mathrm{s}$ at a height slightly below $10 \mathrm{hPa}$. This picture also concurs with the QBO amplitude estimated by Baldwin and Gray [2005] from observational and ERA-40 reanalysis data. Above $1 \mathrm{hPa}, \mathrm{HAMMONIA}$ results show three maxima in the QBO 

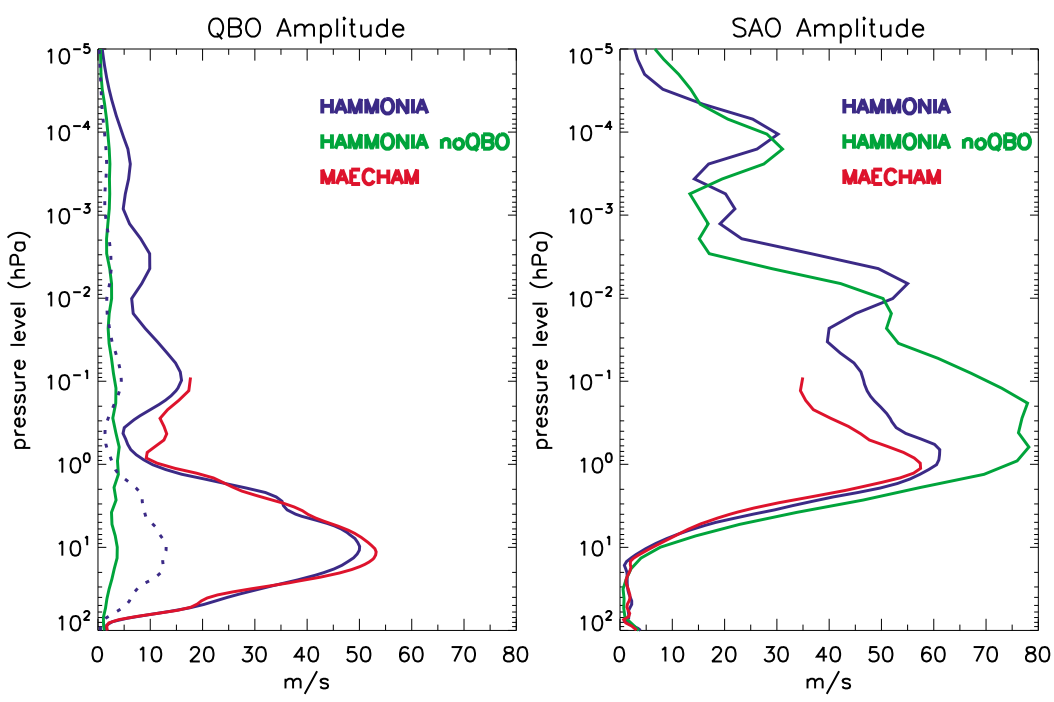

Figure 3. QBO and SAO amplitudes computed for MAECHAM5 (red), and two versions of HAMMONIA, with a QBO (blue) and without a QBO (green). The dotted blue line in the left panel indicates the 99\% confidence level of the QBO amplitude as simulated by the HAMMONIA version with a QBO.

amplitude at around $0.1 \mathrm{hPa}, 0.004 \mathrm{hPa}$, and $0.0003 \mathrm{hPa}$ with values decreasing with height between 17 and $7 \mathrm{~m} / \mathrm{s}$. Since the QBO amplitude is relatively small above $1 \mathrm{hPa}$ a test of significance has been performed through a bootstrapping procedure. One thousand permutations of each of the zonal wind time series have been generated destroying the temporal structure of the data. After that, the procedure followed to compute the QBO amplitude is applied to each of the randomized versions of the original time series. Then, the $99 \%$ confidence level is determined by taking the 99 percentiles of the values obtained. The amplitude of the QBO simulated by HAMMONIA is above the $99 \%$ confidence level at all atmospheric levels between 100 and $10^{-5} \mathrm{hPa}$.

[25] Figure 3 (right) shows close agreement in the amplitude of the SAO in MAECHAM5 and HAMMONIA (model version with internal $\mathrm{QBO}$ ) up to $1 \mathrm{hPa}$ where it has a maximum of around $55 \mathrm{~m} / \mathrm{s}$. In the layer between 1 and $0.1 \mathrm{hPa}$, the amplitude decrease with height to values of around $35 \mathrm{~m} / \mathrm{s}$ and $45 \mathrm{~m} / \mathrm{s}$ in MAECHAM5 and HAMMONIA, respectively. The SAO amplitude in MAECHAM5 shows a good agreement with the amplitude estimated by Baldwin and Gray [2005] from both observational and ERA-40 reanalysis data covering up to $0.1 \mathrm{hPa}$. However, it seems that between 1 and $0.1 \mathrm{hPa}$ HAMMONIA (model version with a QBO) show values $5-10 \mathrm{~m} / \mathrm{s}$ higher than the estimations. In the mesosphere HAMMONIA shows a minimum at around $0.05 \mathrm{hPa}$ of $40 \mathrm{~m} / \mathrm{s}$ and a maximum of $55 \mathrm{~m} / \mathrm{s}$ at $0.01 \mathrm{hPa}$. Above this level the SAO amplitude decreases with height to values around $20 \mathrm{~m} / \mathrm{s}$ in the mesopause region (around $0.001 \mathrm{hPa}$ ). A third maximum of $30 \mathrm{~m} / \mathrm{s}$ approximately is found in the low thermosphere, at around $0.0001 \mathrm{hPa}$.

[26] Comparing the SAO amplitude in the two HAMMONIA simulations (Figure 3, right), with and without a QBO, it is clear that in the simulation without QBO the SAO amplitude is strongly overestimated from the stratopause up to $0.01 \mathrm{hPa}$. Above $0.01 \mathrm{hPa}$ a higher degree of accordance between the two simulations is observed. This result suggests that the QBO strongly modulates the SAO.
Thus it is likely that those models that do not have a QBO will not be able to reproduce a realistic SAO.

\section{Simulated Modulation of the SAO by the QBO}

\subsection{QBO Modulation of the SSAO}

\subsubsection{Modulation of the SSAO by the QBO in MAЕСНАM5}

[27] Consistent with previous studies [Wallace, 1973; Dunkerton and Delisi, 1997; Garcia et al., 1997], Figure 1a shows that the altitude to which SSAO westerlies descend depends on the phase of the QBO. When a QBO westerly phase is centered at around $10 \mathrm{hPa} \mathrm{SSAO}$ westerlies do not propagate below $2 \mathrm{hPa}$. However, they descend to $5 \mathrm{hPa}$ when QBO westerlies weaken in the low stratosphere. It seems that the descent of the SSAO westerlies accompanies the descent of westerly QBO phase. Figure 1a shows a similar behavior for the maximum descent of SSAO easterlies that accompanies the descent of the easterly QBO phase. Garcia et al. [1997] did not observe a QBO modulation of the SSAO easterlies in rocketsonde observations at Kwajalein Island. Although the observations at Kwajalein Island are from about $8^{\circ} \mathrm{N}$, MAECHAM5 results obtained at around $8^{\circ} \mathrm{N}$ (not shown) also shows a clear QBO modulation of the SSAO easterlies in like manner as at the equator.

[28] For an objective identification of the average QBO signals in the SSAO region, Figure 4 depicts the vertical profiles of zonal wind composites for QBO east and west phases at $1.4^{\circ} \mathrm{N}$ for the months of April, October, January, and July. We focus on these months because they are representative of the general features of the interannual variability of the SSAO westerlies and easterlies during the strong (April and January) and weak (October and July) SSAO cycles. Composites have been computed using, separately, sequences of April, October, January, or July zonal wind anomalies. Figure 4 shows composites for both total and deseasonalized zonal-mean zonal winds. To allow a better comparison of the results obtained with both MAECHAM5 and HAMMONIA models, we have defined 
(a) u composites at $1.4 \mathrm{~N}(\mathrm{Apr})$

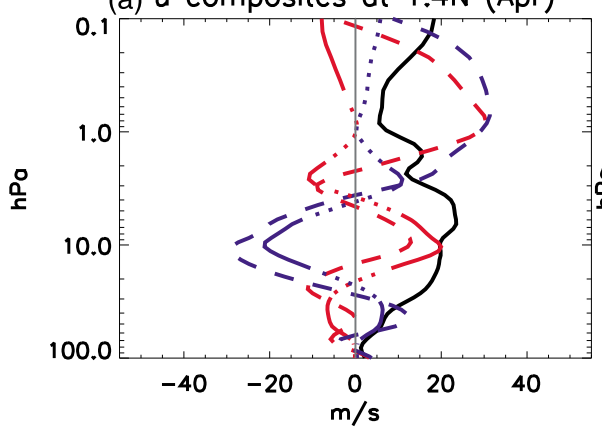

(c) u composites at $1.4 \mathrm{~N}$ (Jan)

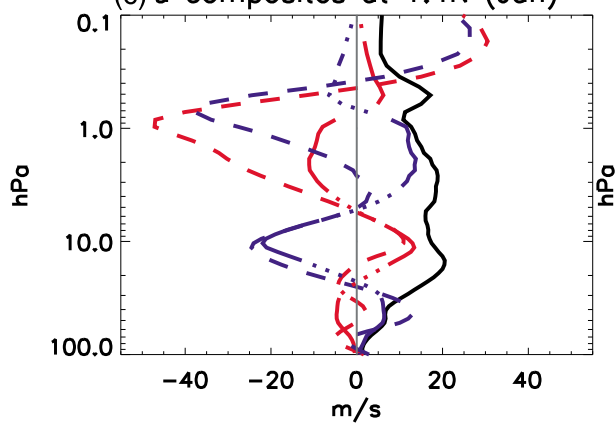

(b) u composites at $1.4 \mathrm{~N}(\mathrm{Oct})$

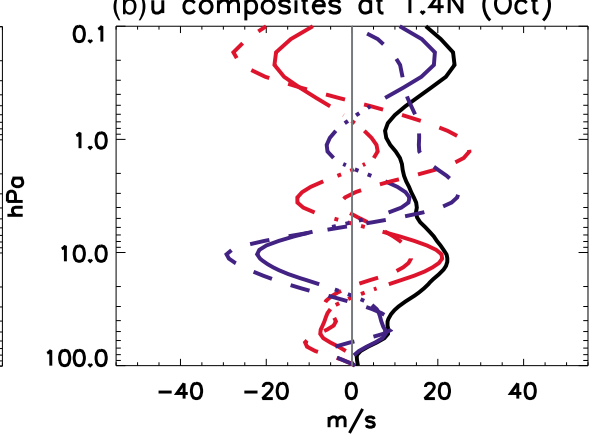

(d) u composites at $1.4 \mathrm{~N}$ (Jul)

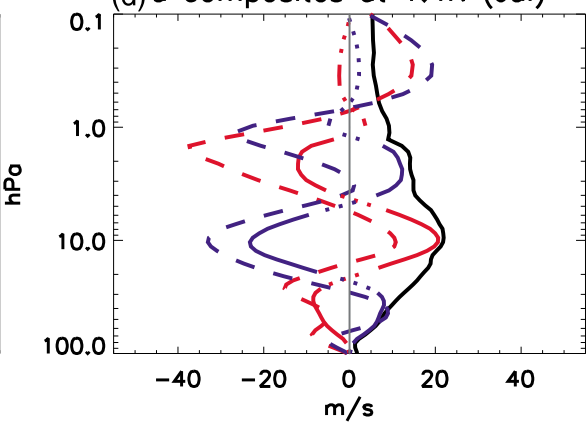

Figure 4. Vertical profiles of composites of zonal winds (dashed) and zonal wind anomalies from the climatological seasonal cycle (solid) for QBO westerly (red) and QBO easterly (blue) cases at $1.4^{\circ} \mathrm{N}$ (in $\mathrm{m} / \mathrm{s}$ ) for (a) April, (b) October, (c) January, and (d) July as simulated by MAECHAM5. Anomalies are only plotted as solid lines where the confidence level is higher than $95 \%$ but as dotted lines where it is below 95\%. The selection criterion for QBO is winds above $5 \mathrm{~m} / \mathrm{s}$ and below $-5 \mathrm{~m} / \mathrm{s}$ at $10 \mathrm{hPa}$ for the westerly and easterly phases, respectively. The black solid line is the standard deviation and the vertical gray line indicates zero wind.

the QBO phase at $10 \mathrm{hPa}$ in all cases. We have chosen $10 \mathrm{hPa}$ because, for most of the analyzed months of the two models, the standard deviation of the equatorial zonal wind maximizes around this level as it can be seen in Figure 4 for MAECHAM 5 and later in Figure 8, the equivalent to Figure 4 but for HAMMONIA data. Defining the QBO at the level with the strongest anomalies maximizes its response above this level, where anomalies reach values close to the standard deviation of the equatorial zonal wind. This is the case for the composites of October and July for MAECHAM5 (Figure 4) and for the composites of April, October, and July for HAMMONIA (Figure 8). In the rest of the cases (April and January for MAECHAM5 and January for HAMMONIA) the QBO response in the stratopause and above is stronger when the QBO phase is defined at a different stratospheric level characterized with greater oscillation amplitude (not shown). However, it is only the magnitude and not the nature of this response what depends on the altitude used to define the QBO (not shown). It has to be kept in mind that the QBO period is seasonally synchronized in the case of HAMMONIA so we have not been free to choose any QBO vertical structure and this represents a limitation for our study. The criterion of monthly mean zonal wind anomalies at $10 \mathrm{hPa}$ of above $5 \mathrm{~m} / \mathrm{s}$ and below $-5 \mathrm{~m} / \mathrm{s}$ has been used to define the westerly (QBOw) and easterly (QBOe) QBO phases, respectively, at each analyzed month. The general characteristics of the results shown were not sensitive to the choice of this threshold.
[29] The statistical significance of the signal related to the QBO has been tested by a Monte Carlo method. With this aim, composites have been computed using, separately, random January, April, October, or July sequences from the whole data series and gathering them into groups with the same number of cases as in the QBO composite we want to test. This procedure has been repeated 1000 times and the resulting random distribution plotted. The sample follows a normal distribution and so, the threshold for which the values of the QBO composites are considered 95\% significant lies at the $5 \%$ tails ( \pm 1.96 standard deviation from the mean) in the Monte Carlo distribution.

[30] Anomaly composites for April (Figure 4a) show a vertical structure with four alternating easterly and westerly maxima from the low stratosphere to $0.1 \mathrm{hPa}$. However, total wind composites show that for both QBOe and QBOw, SSAO westerlies dominate above $3 \mathrm{hPa}$. Thus easterly and westerly wind anomalies above this level appear as a result of the QBO modulation of the SSAO westerlies. The total wind composites show clearly the dependence of the maximum descent of SSAO westerlies on the QBO phase. During QBOe, SSAO westerlies descend to approximately $4 \mathrm{hPa}$, while during QBOw they are significantly weaker at pressure levels below $1 \mathrm{hPa}$.

[31] In October (Figure 4b), the QBO signature is evident throughout the stratosphere and up to $0.1 \mathrm{hPa}$. When westerlies prevail at $10 \mathrm{hPa}$ level, easterly QBO anomalies occur between 5 and $2 \mathrm{hPa}$. In the total wind composites, these 
anomalies appear as a sharp decrease of the SSAO westerlies below about $2 \mathrm{hPa}$. On the other hand, when QBO easterlies dominate at $10 \mathrm{hPa}$, the onset of a new westerly QBO phase above $5 \mathrm{hPa}$ appears as a further downward propagation of SSAO westerlies. As in April, the QBO modulates the level to which the SSAO westerlies descend, and, in this case, the altitude where their maximum wind speed occurs and, but not the maximum wind speed itself.

[32] As in the case of SSAO westerlies, the SSAO easterlies (Figures $4 \mathrm{c}$ and $4 \mathrm{~d}$ ), are modulated by the QBO in terms of the level to which they descend. Here the altitude where their maximum speed occurs also appears modulated. During both strong (January) and weak (July) SSAO cycle, the levels of maximum wind speed and of maximum descent are lower during QBOw than during QBOe. However, in contrast to the SSAO westerlies, also the maximum wind speed itself is modulated, reaching for instance $-45 \mathrm{~m} / \mathrm{s}$ during QBOw and $-35 \mathrm{~m} / \mathrm{s}$ during QBOe.

[33] Figure 5 presents composites of the zonal wind anomalies (contours) and the anomalies of the EliassenPalm (EP) flux divergence from resolved waves (shaded) for April, October, January, and July. The levels for which QBO westerly and easterly phases are defined are the same as in Figure 4. The EP-flux divergence describes the deposition of zonal momentum of those waves resolved by the model. The significance of the signal related to the QBO has been tested by a Monte Carlo method following the same procedure as in Figure 4.

[34] In Figure 5 the sign of the EP flux divergence and wind shear anomalies is generally consistent with what one would expect from filtering of waves by the mean flow. EP flux divergence anomalies form arc-like structures of alternating westerly and easterly forcing on the westerly and easterly shear zones, respectively, throughout the stratosphere and lower mesosphere. This means that resolved waves, besides playing an important role in the forcing of the QBO, also participate in the QBO modulation of the SSAO. The QBOw composite for April (Figure 5a) shows positive EP flux divergence anomalies reaching $0.25 \mathrm{~m} / \mathrm{s} / \mathrm{d}$ on the steepest westerly shear zone centered at $20 \mathrm{hPa}$ approximately. This westerly wave damping occurring in the middle stratosphere necessarily reduces the wave forcing available to generate the SSAO westerlies at upper levels. In fact, negative EP flux divergence anomalies reaching maximum absolute value around $0.5 \mathrm{~m} / \mathrm{s} / \mathrm{d}$ can be identified between 5 and $2 \mathrm{hPa}$, meaning that easterly forcing is occurring in the upper stratosphere, restraining the descent of the SSAO westerlies. In the opposite phase, when QBO easterlies occur at $10 \mathrm{hPa}$ (Figure $5 \mathrm{~b}$ ) westerly waves may propagate without suffering strong damping to the upper stratosphere. Positive EP flux divergence anomalies reaching $0.5 \mathrm{~m} / \mathrm{s} / \mathrm{d}$ between 5 and $2 \mathrm{hPa}$ indicate that at least a part of these waves dissipates in the upper stratosphere enhancing the downward propagation of the SSAO westerlies.

[35] Consistent results are obtained for October (Figures 5c and 5d). During QBOe, easterlies centered at $10 \mathrm{hPa}$ favor the upward propagation of westerly waves up to the westerly shear zone located between 7 and $4 \mathrm{hPa}$ where they dissipate and enhance the downward propagation of the SSAO westerly phase and contribute to the onset of a new QBO phase. During QBOw, the opposite pattern is found: now enhanced westerly wave dissipation above $3 \mathrm{hPa}$, as indicated by the positive EP flux divergence anomalies observed at the westerly shear zone centered at $2 \mathrm{hPa}$. At this level they encounter the SSAO westerly phase (see Figure $4 \mathrm{~b}$ ) and contribute to the strengthening of the westerlies that reach their maximum at around $1 \mathrm{hPa}$ during QBOw.

[36] The role of the small-scale (parameterized) gravity waves and zonal wind advection has been also investigated. Figure 6 display composites of gravity wave drag anomalies for April and October on the first and second row, respectively. The structure and location of the gravity wave dissipation and its concomitant zonal momentum forcing are similar to that of the resolved waves. In this way, westerly (easterly) forcing observed in the shear zones centered at around $5 \mathrm{hPa}$ during the easterly (westerly) phase of the QBO favors (limits) the downward propagation of SSAO westerlies. They are also comparable in magnitude, although gravity waves drag anomalies are generally stronger than EP flux divergence anomalies above $1 \mathrm{hPa}$.

[37] On the other hand, advective tendencies for the months of April and October (Figures 7a, 7b, 7c, and 7d), caused by the secondary meridional circulation [Giorgetta et al., 2006], form forcing structures that are similar in magnitude and shape to the ones of the EP flux divergence but of the opposite sign. In this way, easterly (westerly) tendencies observed on the westerly (easterly) shear zones partly compensate the forcing produced by resolved and small scale gravity waves.

[38] The EP flux divergence and gravity wave drag anomalies for the months of January and July (Figures 5 and 6 , bottom) are consistent with the results obtained for the months of April and October. Westerlies (easterlies) in the middle stratosphere (centered at $10 \mathrm{hPa}$ ) allow the upward propagation of easterly (westerly) waves, leading to the respective forcing in the shear zone above. In the January QBOw composite, this leads to negative EP flux divergence and gravity wave drag anomalies in the easterly shear zone between $10 \mathrm{hPa}$ and $2 \mathrm{hPa}$ indicating easterly wave dissipation at these levels, which strengthens and enhances the downward propagation of the SSAO easterlies. During the opposite phase (QBOe), easterly waves are damped or absorbed as they propagate through QBO easterlies in the middle stratosphere leading to weaker SSAO easterlies below $1 \mathrm{hPa}$. However, for the solstices, results show important differences in the magnitude of the anomalies at latitudes higher than $10^{\circ}$ of the summer hemisphere. There, while EP flux divergence anomalies in the shear zone between $10 \mathrm{hPa}$ and $2 \mathrm{hPa}$, approximately, reach absolute maximum values around $1 \mathrm{~m} / \mathrm{s} / \mathrm{d}$ (Figure 5), gravity wave drag anomalies are always below $0.25 \mathrm{~m} / \mathrm{s} / \mathrm{d}$ (Figure 6). Thus resolved and small-scale gravity waves produce a forcing of similar magnitude in the equatorial region while resolved waves play a more dominant role in the QBO modulation of the SSAO easterlies at higher latitudes.

[39] Momentum advection tendencies for the months of January and July (Figures $7 \mathrm{e}, 7 \mathrm{f}, 7 \mathrm{~g}$, and $7 \mathrm{~h}$ ) are very similar in magnitude and shape to EP flux divergence anomalies but of the opposite sign. Thus for the solstices, advection partially compensates EP flux divergence and gravity waves drag anomalies and the net forcing should have a magnitude similar to that of the gravity wave drag. 
(a)W_composites EPflux divergence April

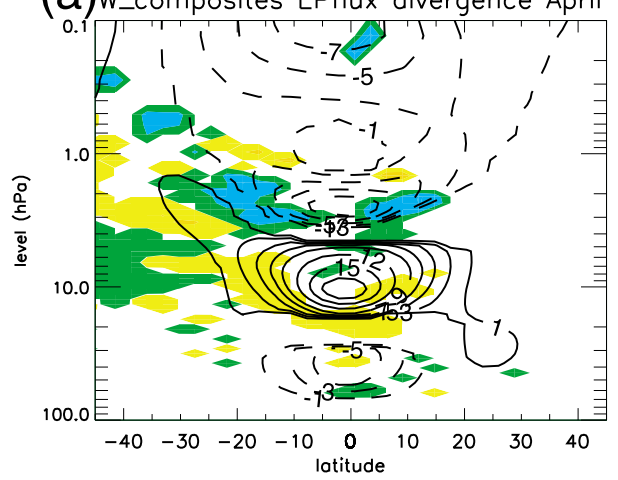

(c) Wheomposites EPflux avergence 0 ctober (d

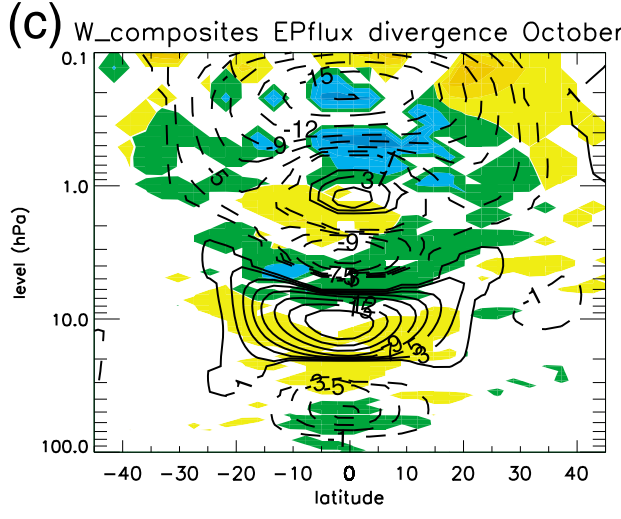

(e) W_composites EPflux divergence January

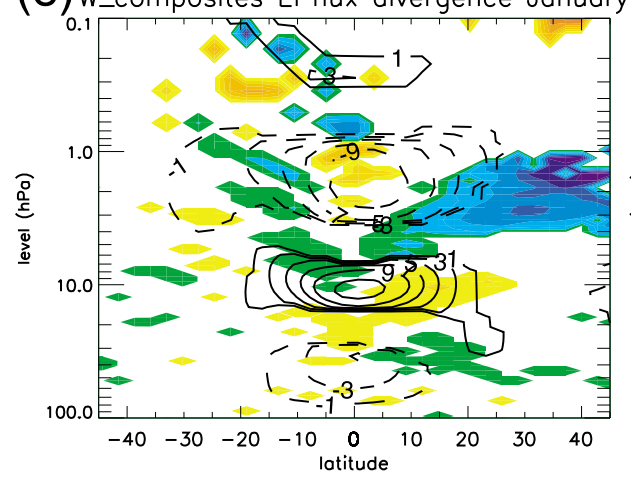

(g) W_composites EPflux divergence July

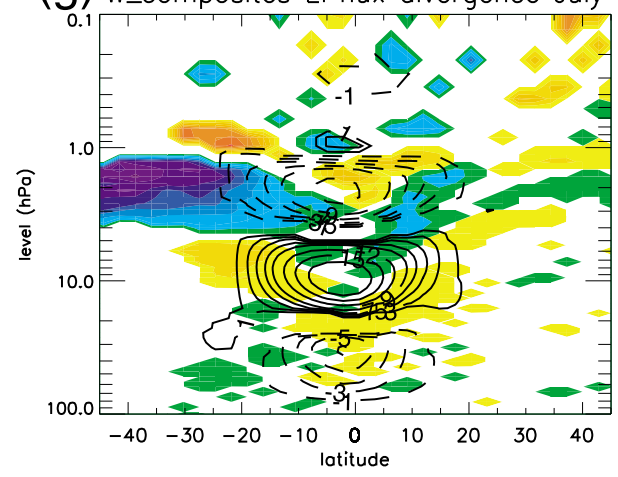

(b) E_composites EPflux divergence April

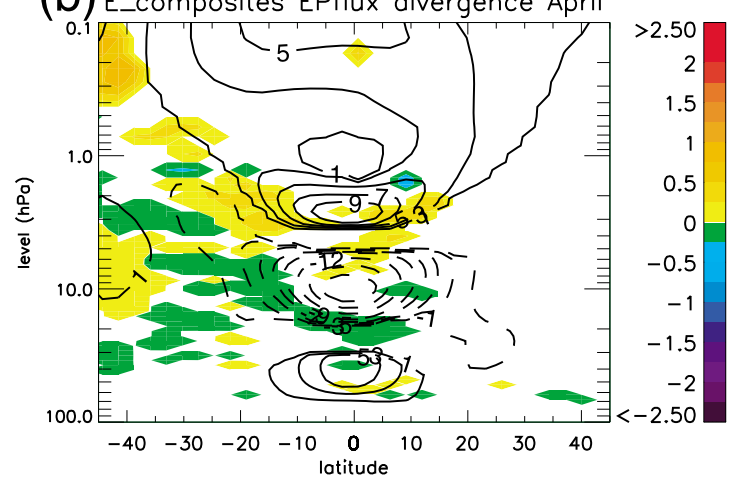

(d) E_composites EPflux divergence October

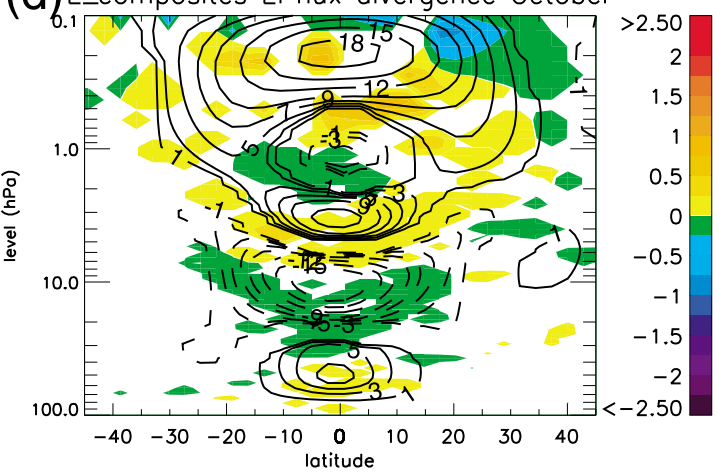

(f) E_composites EPflux divergence January
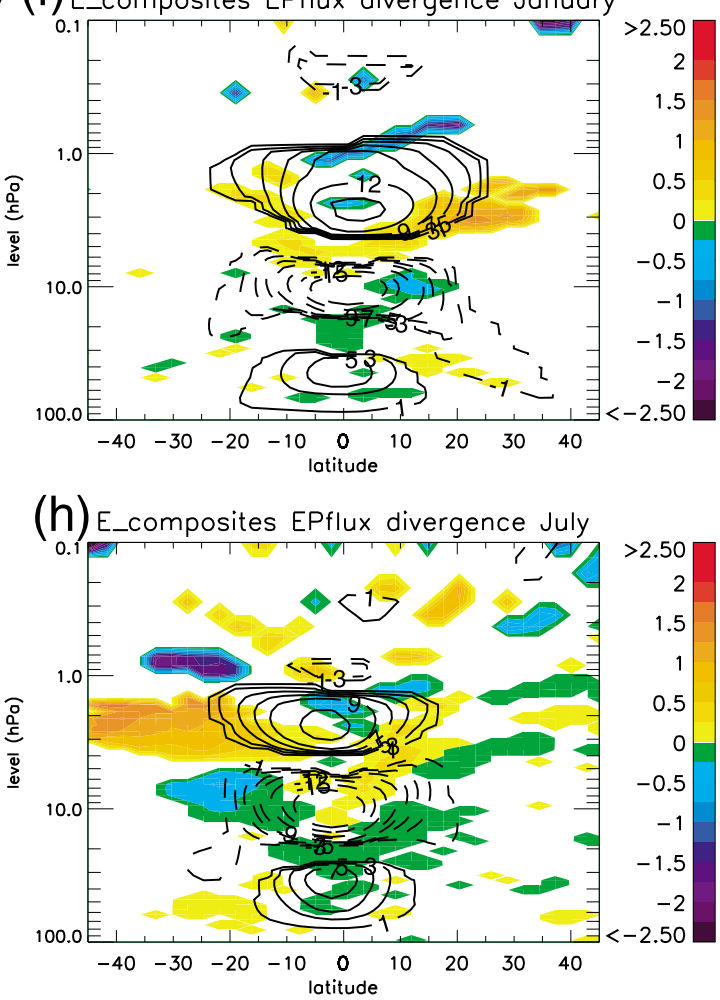

Figure 5. Composites of zonal wind anomalies (contours, $\mathrm{m} / \mathrm{s}$ ) and EP flux divergence anomalies (shaded, $\mathrm{m} / \mathrm{s} /$ day) in MAECHAM5 for April and October. The selection criterion for the different QBO cases is defined in the text. Zonal wind and EP flux divergence anomalies are only shown where the confidence level is higher than $95 \%$. 
(a) W_composites gw drag April

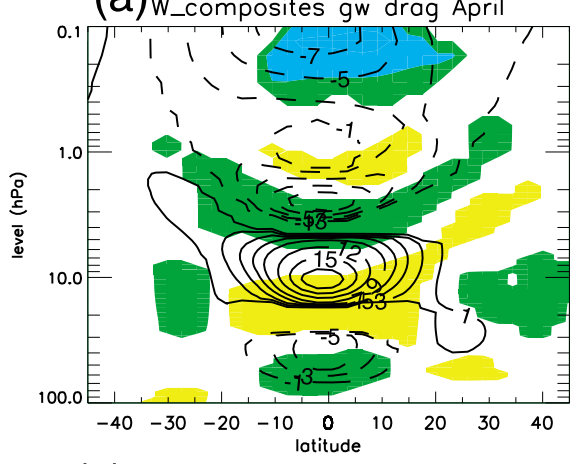

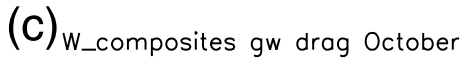

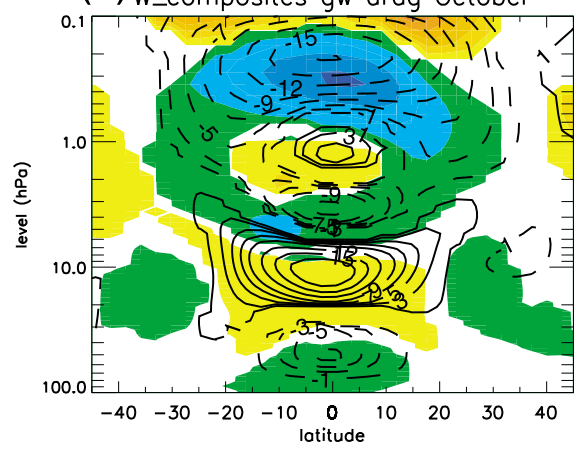

(e) W_composites gw drag January

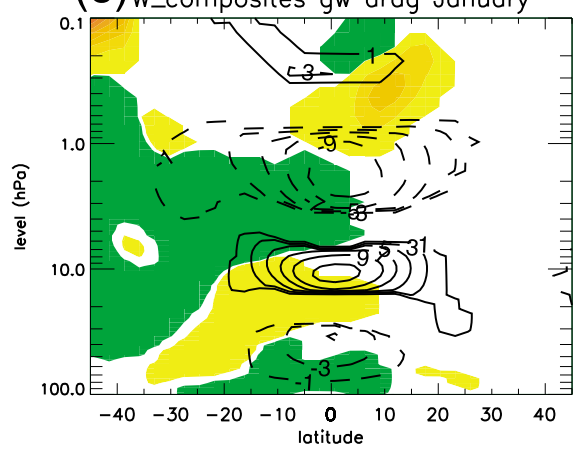

(g) w_composites gw drag July

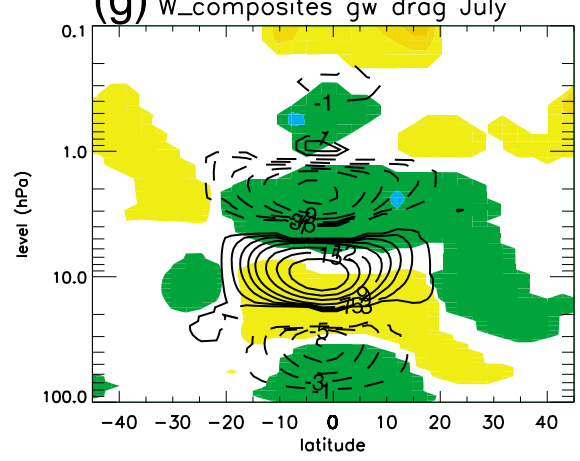

(b) E_composites gw drag April

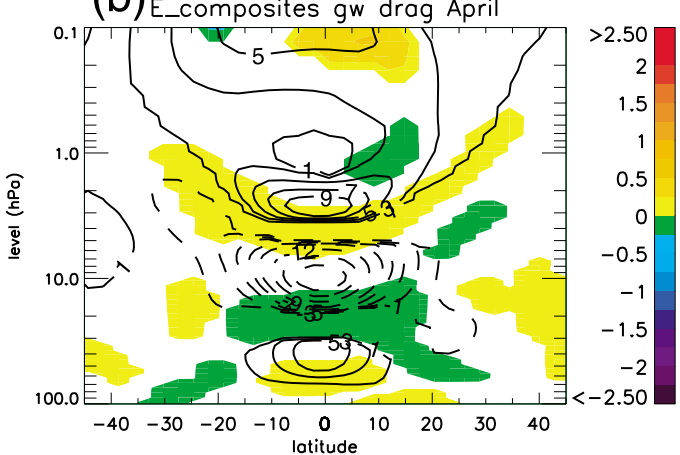

(d) E_composites gw drag October

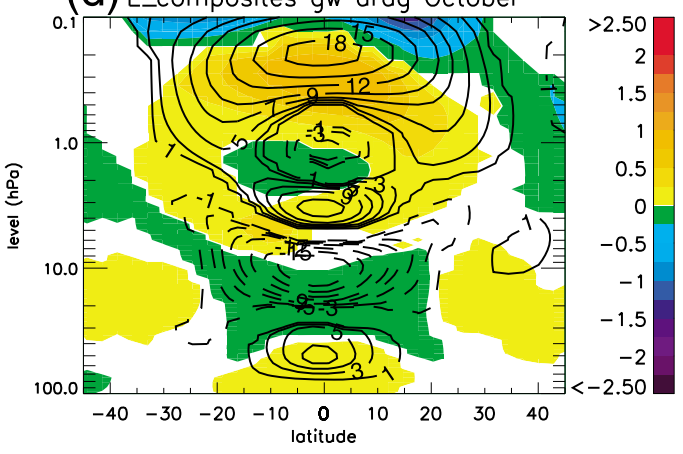

(f) E_composites gw drag January

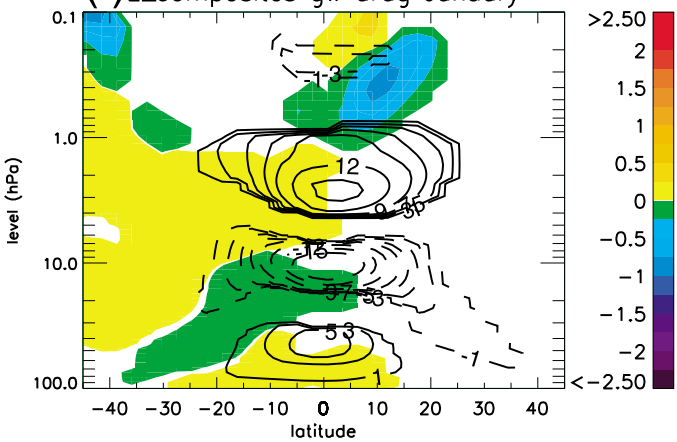

(h) E_composites gw drag July

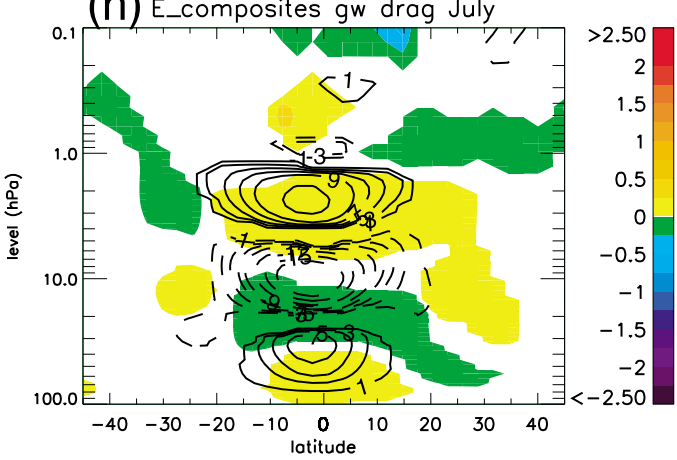

Figure 6. As Figure 5 but shaded regions represent gravity wave drag anomalies (m/s/day).

\subsubsection{Modulation of the SSAO by the QBO in HAMMONIA}

[40] Before analyzing the QBO signature on the MSAO in HAMMONIA (section 3.2), we verify that its simulation of the QBO modulation of the SSAO is consistent with
MAECHAM5 results. As Figure 1 for MAECHAM5, Figure 2 clearly shows that also in HAMMONIA the SSAO maximum descent of westerlies and easterlies winds descends in parallel with the QBO. As for MAECHAM5 (see Figure 4), the SSAO appears prominently modulated by the 
$(a)_{w}$

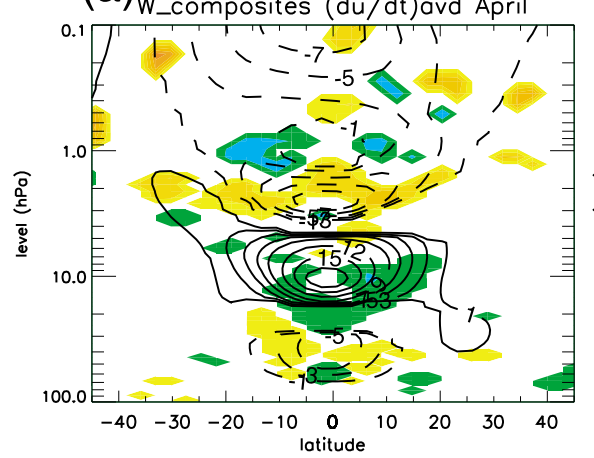

$(\mathrm{c})_{\mathrm{N}-\mathrm{con}}$

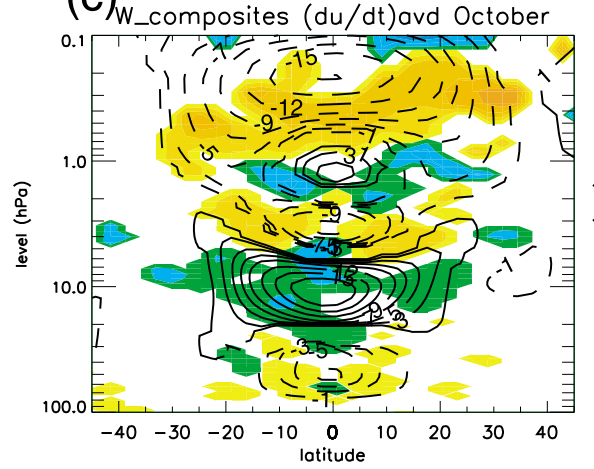

(e)

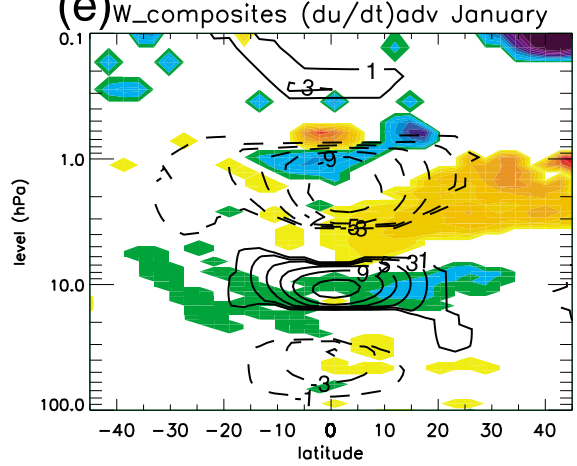

(g) W_composites (du/dt)adv July

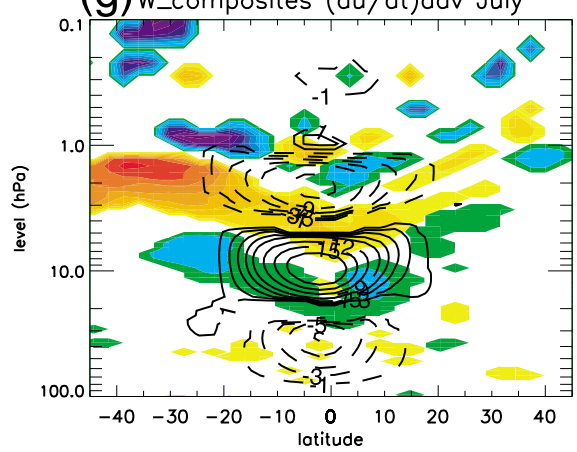

(b) E_composites (du/dt)avd April

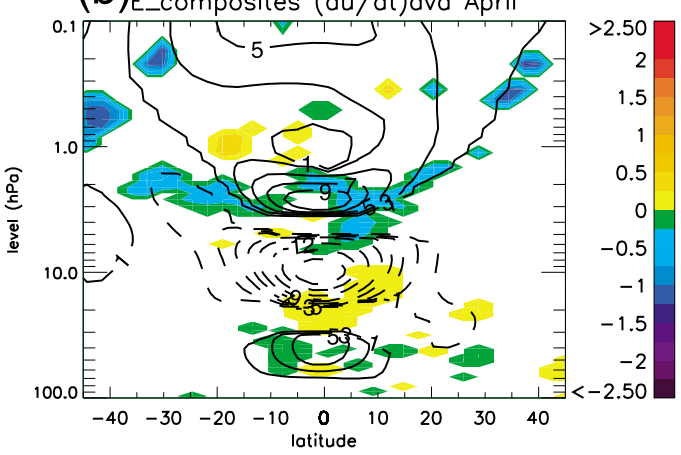

(d) E_composites (du/dt)avd October
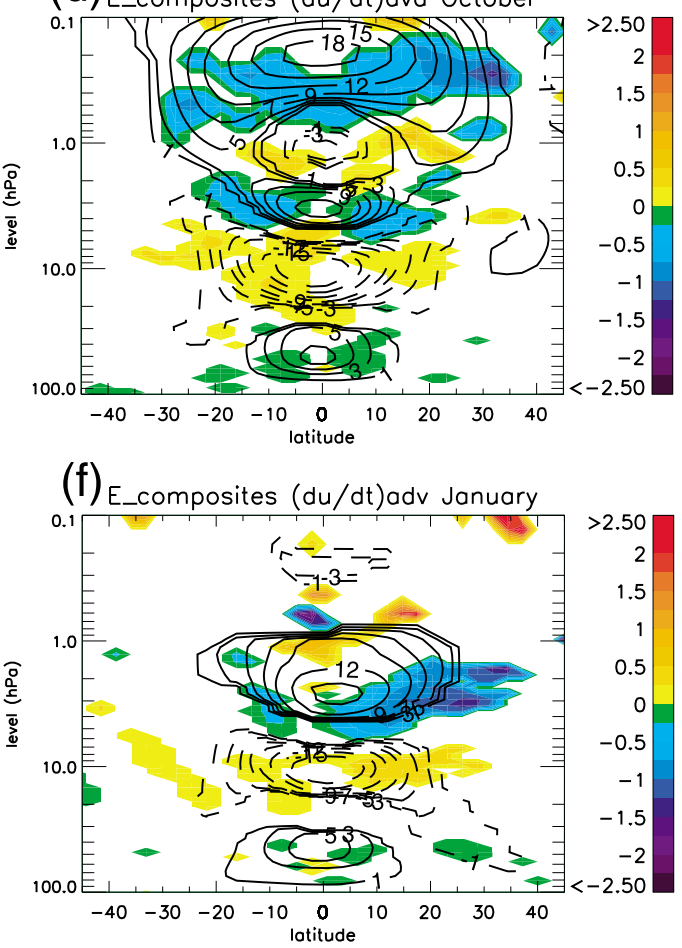

(h)E_composites (du/dt)adv July

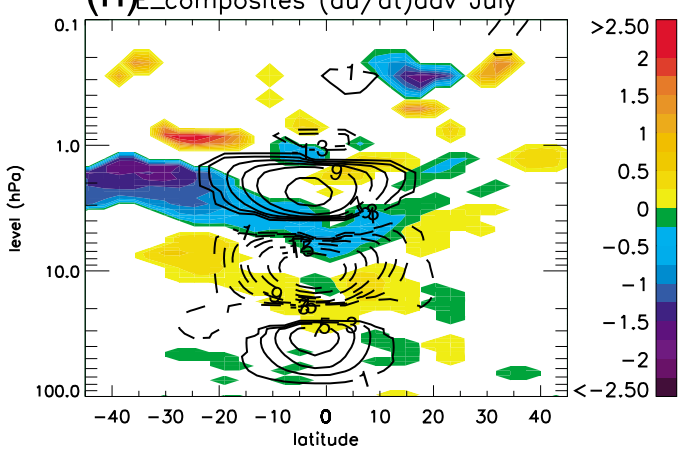

Figure 7. As Figure 5 but shaded regions represent momentum advection anomalies (m/s/day).

QBO. Figure 8 shows that SSAO westerlies (April and October) descend to lower levels when QBO easterlies dominate in the middle stratosphere (around $10 \mathrm{hPa}$ ) while SSAO easterlies (January and July) reach lower altitudes when westerlies prevail in the middle stratosphere. Thus although the QBO in HAMMONIA has an almost regular period of two years, its signature in the upper stratosphere is clearly observed and it is consistent with the MAECHAM5 simulation. 
(a) $u$ composites at $1.8 \mathrm{~N}(\mathrm{Apr})$

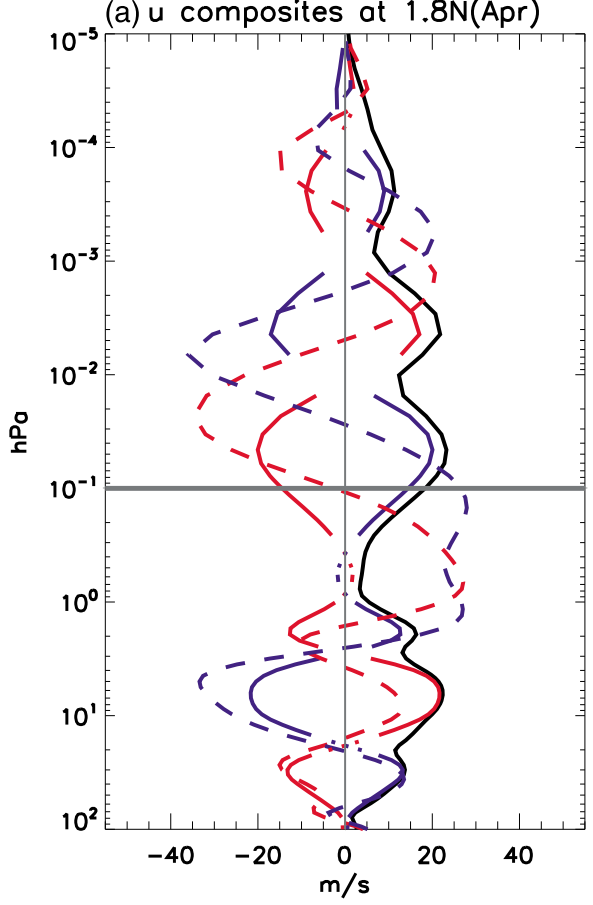

(c) u composites at $1.8 \mathrm{~N}$ (Jan)

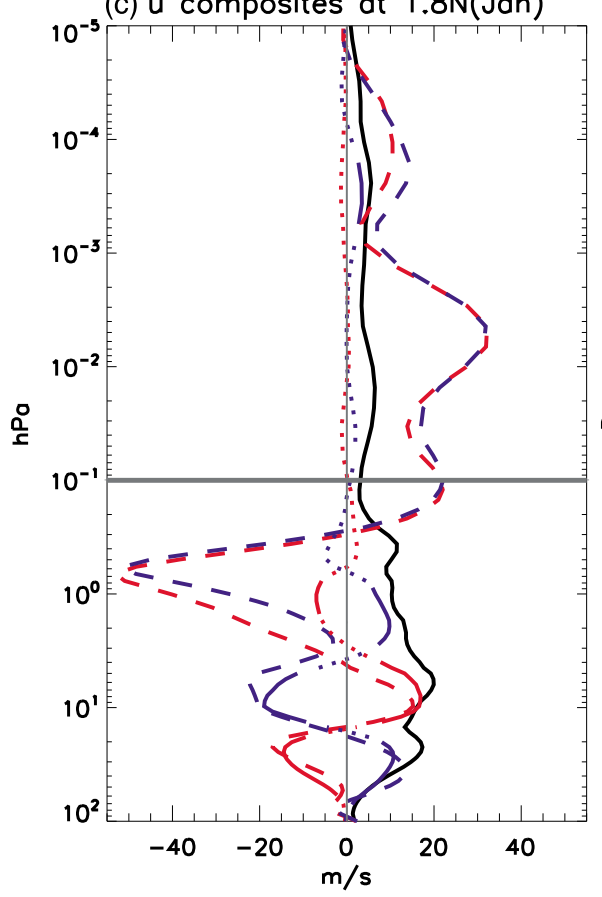

(b) u composites at $1.8 \mathrm{~N}(\mathrm{Oct})$

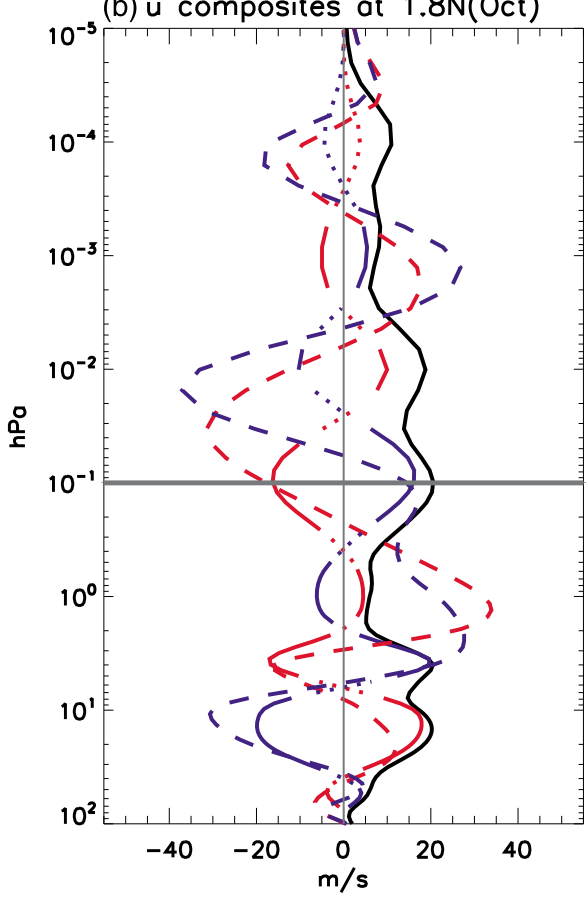

(d) u composites at $1.8 \mathrm{~N}(\mathrm{Jul})$

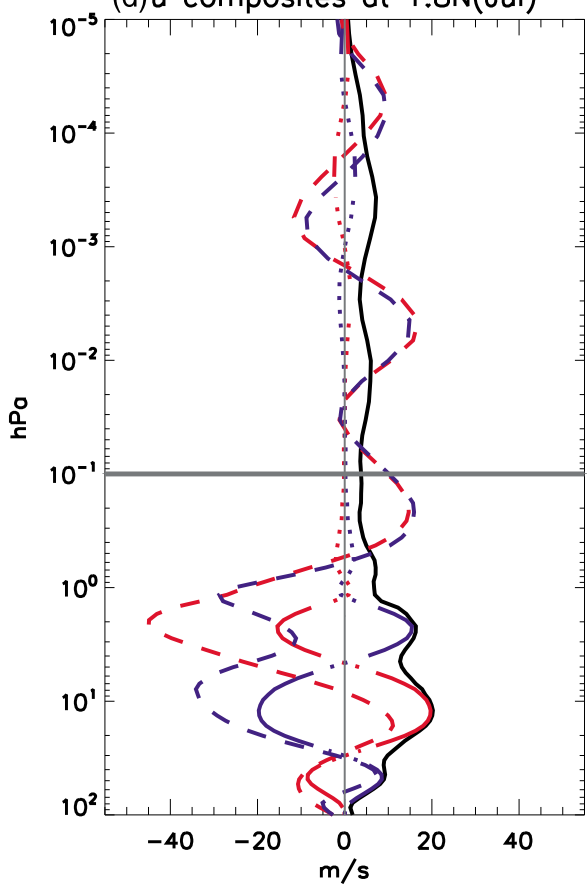

Figure 8. As Figure 4 but for the HAMMONIA simulation. For a better comparison of the results obtained with both HAMMONIA and MAECHAM5, a horizontal gray line at $0.1 \mathrm{hPa}$ indicates the upper limit of the atmospheric layer covered by the MAECHAM5 plots.

\subsection{QBO Modulation of the MSAO in HAMMONIA}

\subsubsection{QBO Modulation of the MSAO Easterlies}

[41] In this section, HAMMONIA data are used to analyze the QBO signature on the MSAO easterlies. In Figure 2, an interannual modulation of the MSAO easterly phase apparently linked to the stratospheric QBO can be identified in the mesosphere. MSAO Easterlies are generated at higher levels when QBO easterlies dominate in the middle stratosphere than when QBO easterlies decay in the low stratosphere.

[42] In Figure 8 we can identify the average QBO effects on the MSAO. Anomaly composites for April show a vertical structure with four alternating easterly and westerly maxima from the stratopause to the low thermosphere significantly linked to the stratospheric QBO. These maxima reach $20 \mathrm{~m} / \mathrm{s}$ at around $0.05 \mathrm{hPa}$ and decrease with altitude. 

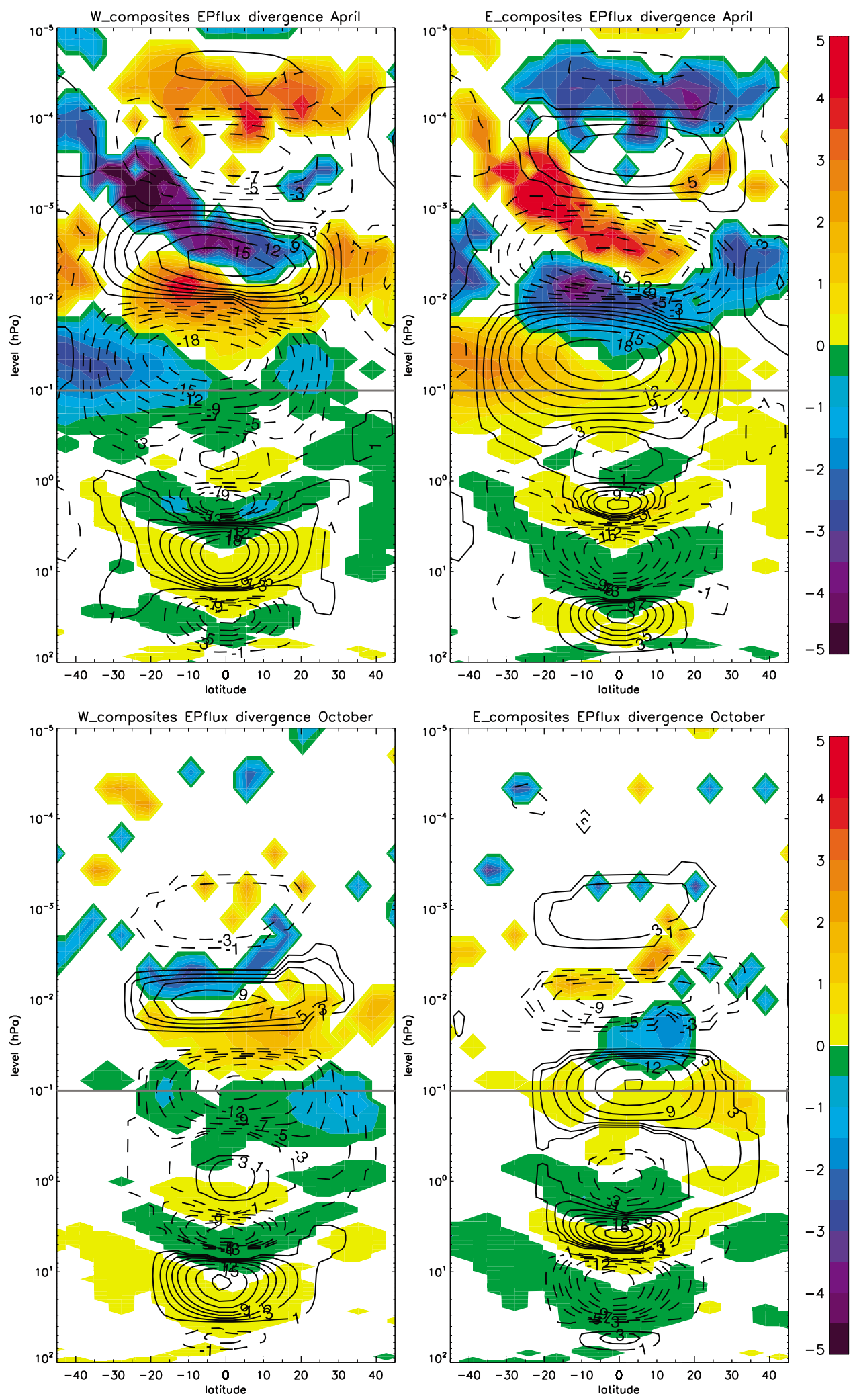

Figure 9. Composites of the zonal wind anomalies (contours, $\mathrm{m} / \mathrm{s}$ ) and EP flux divergence anomalies (shaded, $\mathrm{m} / \mathrm{s} /$ day) in HAMMONIA for April and October. The selection criterion for the different QBO cases is defined in the text. Zonal wind and EP flux divergence anomalies are only shown where the confidence level is higher than $95 \%$. The horizontal gray line at $0.1 \mathrm{hPa}$ indicates the upper limit of the atmospheric layer covered by the MAECHAM5 plots. 

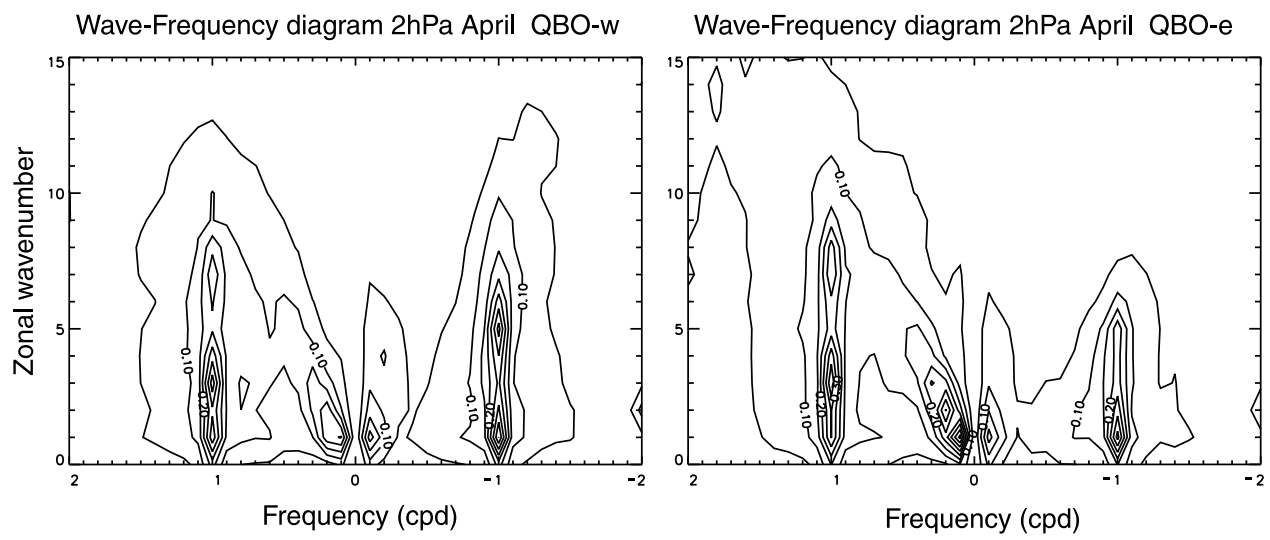

Figure 10. Temperature wave number-frequency diagrams at $2 \mathrm{hPa}$ for April obtained separately for QBOw and QBOe. Positive (negative) frequencies (cycles/day) indicate westerly (easterly) propagating waves.

Mesospheric QBO anomalies are generally weaker in October than in April. There may be different reasons for this. On the one hand, it might be a model artifact caused by the QBO period of about 2 years produced by HAMMONIA that favors a certain QBO wind vertical profile to prevail during particular seasons. On the other hand, it can be due to some other seasonal effect (e.g., tropospheric wave sources).

[43] The QBO modulation of the height at which MSAO easterlies are generated is very evident in the April composites (Figure 8a). MSAO easterlies dominate in the layer between $0.002 \mathrm{hPa}$ and $0.03 \mathrm{hPa}$, when QBO easterlies dominate in the middle stratosphere (QBOe). However, during QBOw, MSAO easterlies are generated at lower levels, around $0.01 \mathrm{hPa}$, and descend to $0.1 \mathrm{hPa}$. A similar QBO modulation of the MSAO easterlies can be seen for October (Figure $8 b$ ). The maximum strength of the MSAO easterlies in HAMMONIA is almost unaffected by the QBO in April. In October, a slight difference is detected as MSAO easterlies are around $5 \mathrm{~m} / \mathrm{s}$ stronger when they appear at higher altitude during QBOe.

[44] As in Figure 5 for MAECHAM5, Figure 9 shows composites of the zonal wind and EP flux divergence anomalies. Westerly and easterly wind anomalies occur at consecutive levels in the tropics. Significant positive and negative EP flux divergence anomalies form arc-like structures on the westerly and easterly shear zones, respectively, throughout the stratosphere and mesosphere (in the case of April even well into the thermosphere) showing that resolved waves contribute to the QBO modulation of the MSAO. Stronger background easterly wind in the stratosphere should produce easterly wave dissipation reducing the easterly forcing available to generate the easterly phase of the MSAO. However, this is difficult to appreciate from Figure 9 because alternating layers of positive and negative EP flux divergence anomalies occur below the layer of the MSAO in both easterly and westerly composites. To better appreciate the QBO modulation of the upward propagating waves, Figure 10 shows wave number-frequency spectra of temperature variations at $2 \mathrm{hPa}$. The spectra are calculated for all months of April and averaged separately for those years with QBOw and QBOe in April, using the same criterion to define the QBO phases as in previous figures. They confirm that the variance associated with easterly inertia- gravity waves (frequency $-1 \mathrm{cpd}$ ) is reduced, during QBOe, when strong QBO easterlies occur in the middle stratosphere. This reduction appears strongest at wave numbers from 5 to 13 that correspond to phase velocities of about -90 to $-35 \mathrm{~m} / \mathrm{s}$. Clearly, these easterly waves have been damped or even absorbed by the QBO easterlies. Mesospheric SAO easterlies are then weaker or occur at upper levels where a weaker wave activity can produce a stronger forcing due to a lower air density. On the other hand, westerlies in the middle stratosphere produce a weaker damping on easterly waves allowing the forcing of the SAO easterlies at lower levels.

[45] The simulated role of small-scale gravity waves in the QBO modulation of the MSAO easterlies is different form that of the resolved waves. Figure 11 shows that in April the westerly (easterly) composite shows significant easterly (westerly) drag throughout the tropical mesosphere and low thermosphere, independent of the local wind shear. This is due to the fact that the filtering in the stratosphere is so dominant that it always produces anomalies of the same sign above the stratosphere. In this way, the easterly mesospheric drag during the westerly QBO phase will contribute to the anomalous forcing of the MSAO easterlies. In October, the forcing due to small-scale gravity waves is weaker than in April.

[46] Figure 12 shows the composites of the simulated momentum advection. Throughout the mesosphere the morphology of the advective tendencies is similar to the ones of the EP flux divergence (Figure 9) but of the opposite sign. Where MSAO easterlies occur in the mesosphere during April and October, easterly (westerly) tendencies are observed on the westerly (easterly) shear zones. Thus as was the case for the SSAO in MAECHAM5 simulation, the advective tendencies partially compensate the equatorial wave forcing.

\subsubsection{QBO Modulation of the MSAO Westerlies}

[47] The QBO signature extends to the mesopause region and above during the equinoxes and modulates the westerly phase of the MSAO occurring above MSAO easterlies. In April (Figure 8a) the altitude at which the mesopause westerlies are generated is modulated by the QBO. While they are found at the layer $0.0001-0.002 \mathrm{hPa}$ during the QBOe, they occur at a lower altitude, in the layer 0.005- 

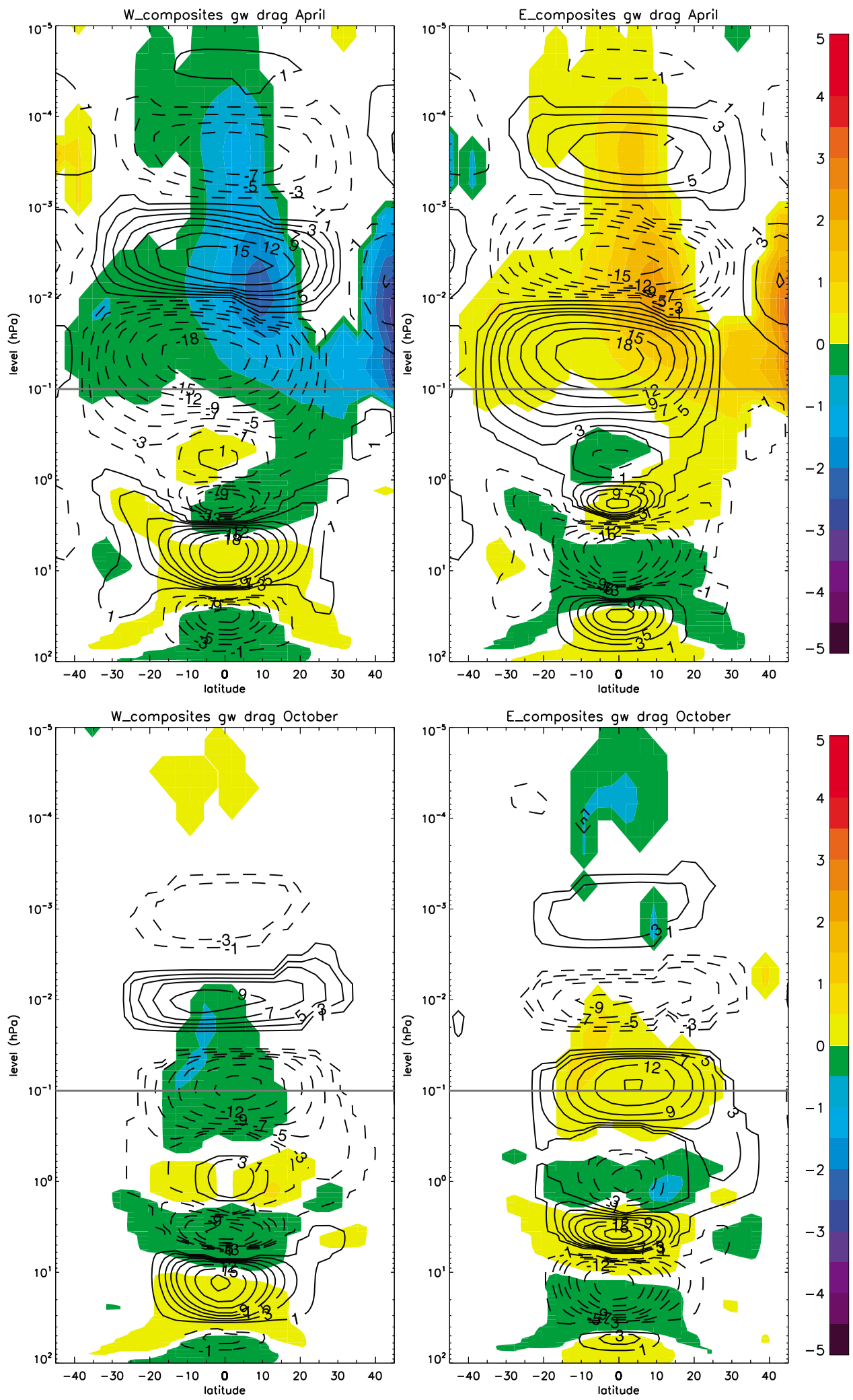

Figure 11. As Figure 9 but shaded regions represent gravity wave drag anomalies $(\mathrm{m} / \mathrm{s} /$ day).

$0.0003 \mathrm{hPa}$, during $\mathrm{QBOw}$. A possible mechanism to explain this QBO effect is based in the filtering of westerly waves by westerlies occurring in the lower mesosphere. Total wind composites for April (Figure 8a) reveal that as a result of a lesser descent of the MSAO easterlies, westerlies in the lower mesosphere prevails up to $0.03 \mathrm{hPa}$ during QBOe (Figure 8a) while the wind turn easterly from $0.1 \mathrm{hPa}$ during QBOw (Figure 8a). The occurrence of stronger 

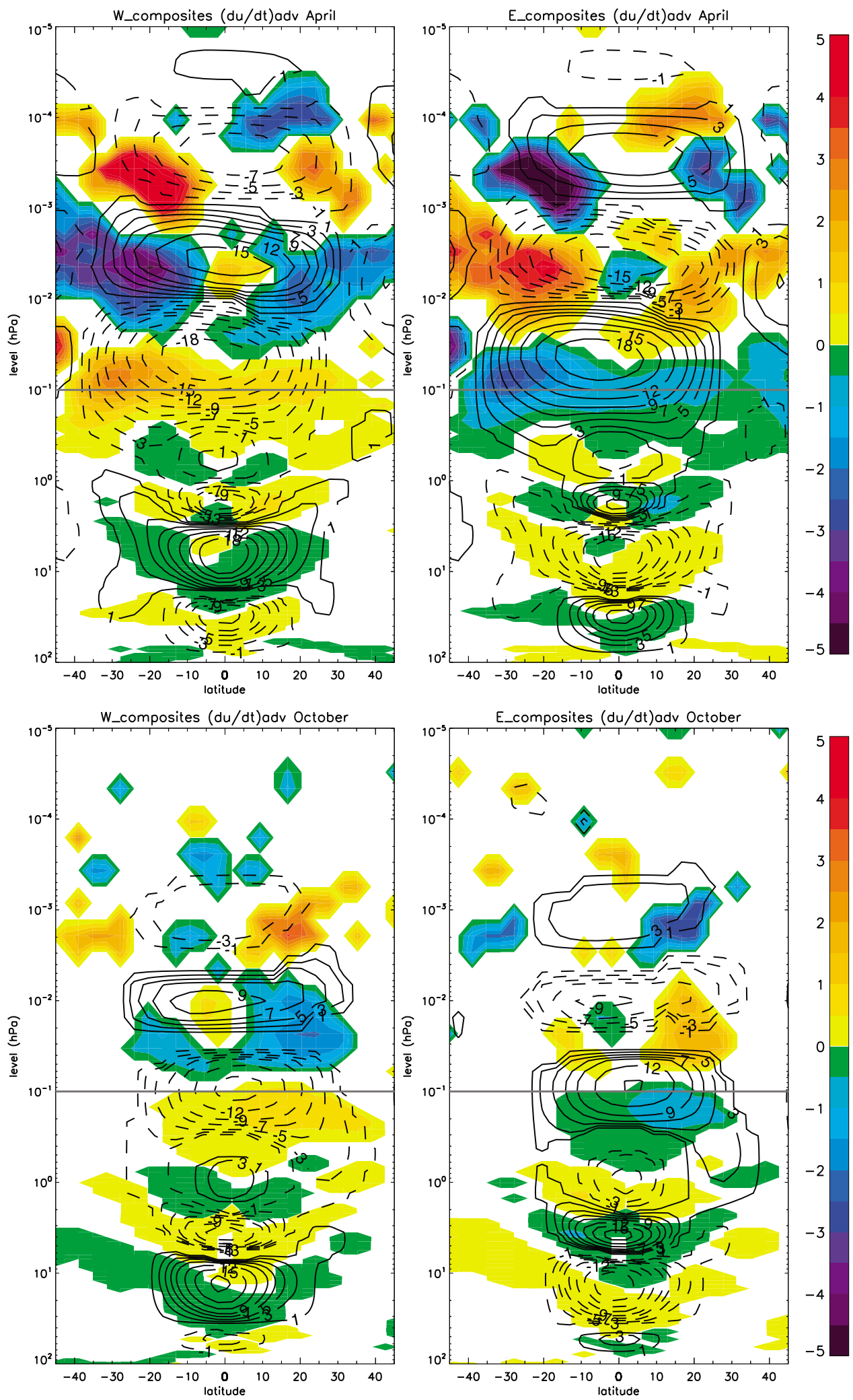

Figure 12. As Figure 9 but shaded regions represent momentum advection anomalies ( $\mathrm{m} / \mathrm{s} / \mathrm{day})$.

westerlies in the layer $0.3-0.03 \mathrm{hPa}$ during QBOe, where the total wind composite shows averaged winds above $25 \mathrm{~m} / \mathrm{s}$, should produce a stronger dissipation of resolved westerly waves. This is shown in Figure 9 (top right) where positive
EP flux divergence anomalies appear on the westerly shear zone between 0.3 and $0.03 \mathrm{hPa}$, approximately, during QBOe. This suggests that stronger westerly background in the lower mesosphere during QBOe produces westerly wave 
dissipation that reduces the westerly forcing available to generate MSAO westerlies in the mesopause region. As a result westerlies occur at a higher altitude where a lower air density allows a weaker wave activity to force the wind.

[48] In the mesopause region we should also take into account the forcing coming from small scale gravity waves. Figure 11 shows westerly (easterly) gravity wave drag during QBOe (QBOw) at the mesopause, where these anomalies are around $2 \mathrm{~m} / \mathrm{s} / \mathrm{d}$ while EP flux divergence anomalies can be above $4 \mathrm{~m} / \mathrm{s} / \mathrm{d}$. Also, Figure 12 reveals that the QBO signature on the momentum advection is weaker than the EP flux divergence in the mesopause region. Thus the forcing of the QBO anomalies at this altitude comes mainly from resolved waves.

[49] The QBO signature on the MSAO westerlies in the mesopause region is weaker in October (Figure 8b). This could be due to the fact that QBO anomalies in the lower mesosphere, centered at $0.1 \mathrm{hPa}$, that appear as a result of the QBO modulation of the altitude of the MSAO easterly wind layer, are weaker in October than in April. As a consequence, EP flux divergence anomalies in the shear zone between 1 and $0.1 \mathrm{hPa}$ are also weaker in October than in April (Figure 9) meaning that a wider spectrum of waves to is allowed to propagate upward. Hence the average momentum of the waves being able to propagate through the MSAO easterly wind layer depends more strongly on the QBO phase in April than in October. In October, the QBO hardly modulates the altitude of mesopause westerlies but produces a slight modulation of their maximum amplitude (Figure 8b).

[50] During the solstices, SSAO easterlies prevail in the stratopause region and MSAO westerlies dominate in the middle and upper mesosphere (Figure 2). Figures 8c and 8d reveal that the QBO signature in the mesosphere almost vanishes during the months of January and July and the simulated MSAO westerlies are not modulated by the stratospheric QBO. This is consistent with the work by Garcia and Sassi [1999] who suggested that stratospheric QBO westerlies are too weak to modulate the MSAO westerlies.

\section{Summary and Discussion}

[51] The QBO signature in the upper stratosphere, mesosphere and lower thermosphere is analyzed from the MAECHAM5 and HAMMONIA general circulation models. Consistent with previous studies [e.g., Pascoe et al., 2005] the QBO is the dominant feature of the stratospheric climatology between about 80 and $5 \mathrm{hPa}$ in both models. From $5 \mathrm{hPa}$ to the mesopause region the variability is dominated by a SAO. Our results suggest that the QBO in the stratopause, mesosphere, and lower thermosphere is linked to the stratospheric QBO. They show that, above the stratosphere, the QBO strongly modulates the SAO westerly and easterly winds.

[52] In accordance with previous studies [Wallace, 1973; Dunkerton and Delisi, 1997] our results reveal a systematic tendency for the SSAO westerlies to descend lower as QBO westerlies decay in the lower stratosphere. As observed by Garcia et al. [1997], we show that it is the altitude of maximum descent and not the strength of the SSAO west- erlies that is modulated by the QBO. This modulation is simulated for both the weak and the strong SSAO cycles.

[53] Garcia et al. [1997] hypothesized that small-scale gravity waves as well as planetary and intermediate-scale Kelvin waves and intermediate- and small-scale inertiagravity waves with phase speeds comparable to the QBO westerlies may influence the SSAO westerlies through a modulation of the vertical propagation of the waves by the QBO. Our results demonstrate that both resolved waves (up to the truncation limit at wave number 42) and small-scale gravity waves contribute to the QBO modulation of the SSAO westerlies. Our results show that the forcing provided by both kinds of waves and also by momentum advection is comparable in magnitude. Garcia et al. [1997] hypothesized that seasonal variation in small-scale gravity wave sources is important for the QBO modulation of the SSAO westerlies. In HAMMONIA the gravity wave source function is constant in space and time. However, the launch level of the parameterized gravity waves is $671 \mathrm{hPa}$ and thus seasonal variations in tropospheric winds above this level impart an effective seasonality to the gravity wave forcing. In this way, the gravity wave drag above the tropopause has a seasonal variation imparted by tropospheric filtering that could be considered as an effective source variation, although, in a strict sense, the sources do not vary.

[54] Our results suggest that the QBO modulates the altitude of maximum descent and also the strength of the SSAO easterly phase during both the strong and the weak SSAO cycle. QBO modulation of the SSAO easterlies has not been observed. Hence this feature might be an artifact of our simulations due to an overestimation of the contribution of the resolved and small-scale waves to the forcing of the SSAO easterlies but it might also have remained undetected due to deficiencies of the existing data sets. HRDI and rocketsonde observations analyzed by Garcia et al. [1997] did not reveal any interaction between the QBO and the SSAO easterly phase. On the other hand, previous analyses of ERA-40 reanalysis data [Pascoe et al., 2005; Calvo et al., 2007; Peña-Ortiz et al., 2008] have identified a third QBO phase in the upper stratosphere. This is also detectable during the northern winter, when SSAO easterlies dominate in this region. Thus this finding is in accordance with our simulation of the SSAO easterly phase being modulated by the QBO.

[55] As for the SSAO westerlies, small-scale gravity waves and resolved waves contribute to the forcing of the QBO modulation of the SSAO easterlies. Our results show that resolved waves produce the strongest forcing and that momentum advection partially balanced the forcing due to resolved and small-scale waves.

[56] The results obtained with HAMMONIA show that the upward propagation of the QBO signature above the stratopause strongly depends on the seasonal cycle. During the solstices, MSAO westerlies prevail in the mesosphere and the QBO signature is only observed around the stratopause, where SSAO easterlies dominate. This result confirm that MSAO westerlies are not directly modulated by the stratospheric QBO, which is consistent with Garcia and Sassi [1999] who suggested that QBO westerlies are too weak to modulate mesospheric SAO westerlies. However, during the equinoxes, when MSAO easterlies appear in the middle mesosphere, the QBO signature extends throughout 


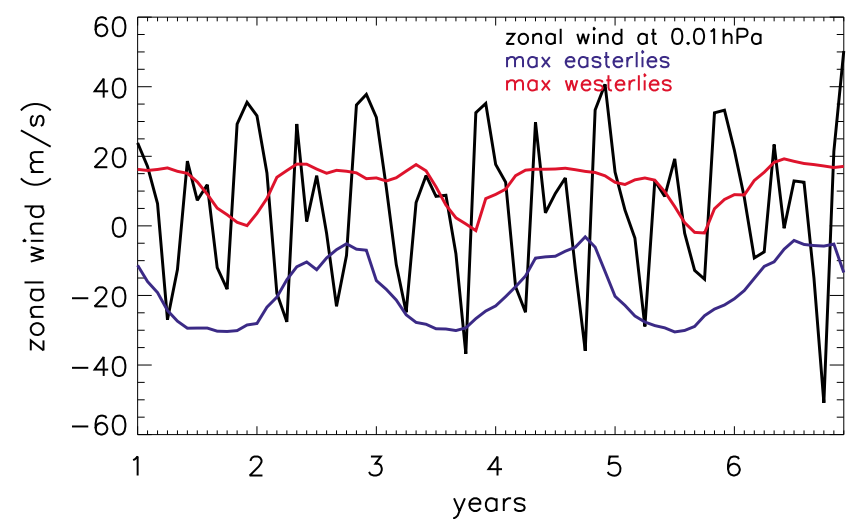

Figure 13. Comparison of the wind at $0.01 \mathrm{hPa}(\sim 85 \mathrm{Km})$ with the strongest easterlies and westerlies in the layer 10 $70 \mathrm{hPa}$ for six arbitrarily chosen years of the HAMMONIA simulation.

the mesosphere and low thermosphere being stronger during the vernal equinox. Previous studies found a QBO signature in the upper mesosphere and lower thermosphere as a modulation of the amplitude of the diurnal tide primarily observed during the vernal equinoxes [Vincent et al., 1998; Hagan et al., 1999; Xu et al., 2009]. The origin and mechanism that generates this signature has not been identified. However, the study of the QBO effects on the diurnal tide is out of the scope of the present paper.

[57] Results reveal that MSAO easterlies in April and October are generated at a higher altitude, above $0.01 \mathrm{hPa}$, when strong QBO easterlies dominate in the middle stratosphere. However, they occur above $0.1 \mathrm{hPa}$ when QBO easterlies decay in the low stratosphere. Garcia et al. [1997] used data from HRDI and radar observations to show that stronger MSAO easterlies occurred when strong westerlies were present in the stratosphere and vice versa. However, this relationship was not always evident and weak MSAO easterlies were also found when strong westerlies prevailed in the stratosphere. The results presented here and those shown by Garcia et al. [1997] are not directly comparable because we have defined the QBO phase at $10 \mathrm{hPa}$ while Garcia et al. [1997] observed the strengthening of the easterlies when westerlies occurred around $30 \mathrm{hPa}$. Unfortunately, the seasonally synchronized QBO in HAMMONIA impedes choosing any QBO vertical structure for analysis in any given season. For a better comparison of the results, we have produced Figure 11 from Garcia et al. [1997] for HAMMONIA data (Figure 13). Figure 13 shows the strongest easterlies and westerlies in the layer $10-70 \mathrm{hPa}$ and the wind at $0.01 \mathrm{hPa}(\sim 85 \mathrm{Km})$ for six arbitrarily chosen years of the HAMMONIA simulation. Although in some cases strong easterlies at $0.01 \mathrm{hPa}$ coincide with a period of deep QBO westerlies, especially in the years 4 and 6 , no systematic connection is found between the strengthening of MSAO easterlies at $0.01 \mathrm{hPa}$ and the occurrence of deep westerlies in the layer $10-70 \mathrm{hPa}$ when the whole 30 -year data set was examined. Owing to the QBO modulation of the height of the MSAO easterlies in HAMMONIA it is difficult to evaluate how the QBO might affect the strength of the MASO easterly phase from the wind at a single level (at $0.01 \mathrm{hPa}$ in this case). However, the comparison of the results obtained with modeling and observational data reveal that Figure 11 from Garcia et al. [1997] would be compatible with a QBO modulation of the height of the MSAO easterlies. It would be necessary to have observational data covering a longer time period to evaluate in what degree the QBO affects the amplitude and/or the height of the MSAO easterly phase.

[58] We have shown that selective filtering of waves that propagate through the QBO winds can modulate the easterly phase of the MSAO. Easterly inertia-gravity waves of phase speeds between about -90 and $-35 \mathrm{~m} / \mathrm{s}$ are strongly damped when QBO easterlies occur in the middle and upper stratosphere. Our results also show that small scale gravity waves do contribute to the mesospheric QBO simulated by HAMMONIA. Previously, Garcia and Sassi [1999], Burrage et al. [1996], and Mengel et al. [1995] used numerical models to suggest that inertia gravity waves and also small gravity waves could have a role in the forcing of the QBO signature on the MSAO. We now confirm their results in a more realistic general circulation model as HAMMONIA.

[59] Our results detect a QBO effect on the westerly phase of the MSAO dominating in the mesopause region and low thermosphere during the equinoxes. We suggest that this could be due to the filtering of westerly waves by the westerly wind layer occurring in the lower mesosphere whose strength and thickness depends on the QBO phase.

\section{References}

Baldwin, M. P., and L. J. Gray (2005), Tropical stratospheric winds in ECMWF ERA-40 reanalysis, rocketsonde data, and rawinsonde data, Geophys. Res. Lett., 32(9), L09806, doi:10.1029/2004GL022328.

Burrage, M. D., R. A. Vincent, H. G. Mayr, W. R. Skinner, N. F. Arnold, and P. Hays (1996), B. Long-term variability in the equatorial middle atmosphere zonal wind, J. Geophys. Res., 101, 12,847-12,854, doi:10.1029/ 96JD00575.

Calvo, N., M. A. Giorgetta, and C. Peña-Ortiz (2007), Sensitivity of the boreal winter circulation in the middle atmosphere to the quasi-biennial oscillation in MAECHAM5 simulations, J. Geophys. Res., 112, D10124, doi:10.1029/2006JD007844.

Delisi, D. P., and T. J. Dunkerton (1988), Seasonal variation of the semiannual oscillation, J. Atmos. Sci., 45(19), 2772-2809, doi:10.1175/ 1520-0469(1988)045<2772:SVOTSO $>2.0 . \mathrm{CO} ; 2$.

Dunkerton, T. J., and D. P. Delisi (1997), Interaction of the quasi-biennial oscillation and stratopause semiannual oscillation, J. Geophys. Res., 102, 26,107-26,116, doi:10.1029/96JD03678.

Garcia, R. R., and F. Sassi (1999), Modulation of the semiannual oscillation by the quasibiennial oscillation, Earth Planets Space, 51, 563-570.

Garcia, R. R., T. J. Dunkerton, R. S. Lieberman, and R. A. Vincent (1997), Climatology of the semiannual oscillation of the tropical middle atmosphere, J. Geophys. Res., 102(D22), 26,019-26,032, doi:10.1029/ 97JD00207.

Giorgetta, M. A., E. Manzini, and E. Roeckner (2002), Forcing of the quasi-biennial oscillation from a broad spectrum of atmospheric waves, Geophys. Res. Lett., 29(8), 1245, doi:10.1029/2002GL014756.

Giorgetta, M. A., E. Manzini, E. Roeckner, M. Esch, and L. Bengtsson (2006), Climatology and forcing of the quasi-biennial oscillation in the MAECHAM5 model, J. Clim., 19(16), 3882-3901, doi:10.1175/ JCLI3830.1.

Hagan, M. E., M. D. Burrage, J. M. Forbes, J. Hackney, W. J. Randel, and X. Zhang (1999), QBO effects on the diurnal tide in the upper atmosphere, Earth Planets Space, 51, 571-578.

Hamilton, K. (1986), Dynamics of the stratospheric semiannual oscillation, J. Meteor. Soc. Jpn., 64, 227-244.

Hines, C. O. (1997a), Doppler-spread parameterization of gravity wave momentum deposition in the middle atmosphere. Part 1: Basic formulation, J. Atmos. Sol. Terr. Phys., 59, 371-386, doi:10.1016/S1364-6826 (96)00079-X.

Hines, C. O. (1997b), Doppler-spread parameterization of gravity wave momentum deposition in the middle atmosphere. Part 2: Broad and quasi 
monochromatic spectra, and implementation, J. Atmos. Sol. Terr. Phys., 59, 387-400, doi:10.1016/S1364-6826(96)00080-6.

Hirota, I. (1978), Equatorial waves in the upper stratosphere and mesosphere in relation to the semiannual oscillation of the zonal mean wind J. Atmos. Sci., 35, 714-722, doi:10.1175/1520-0469(1978)035<0714: EWITUS $>2.0 . \mathrm{CO} ; 2$.

Hitchman, M. H., and C. B. Leovy (1988), Estimation of the Kelvin wave contribution to the semiannual oscillation, J. Atmos. Sci., 45, 1462-1475, doi:10.1175/1520-0469(1988)045<1462:EOTKWC > 2.0.CO;2.

Holton, J. R., and W. M. Wehrbein (1980), Numerical model of the zonal mean circulation of the middle atmosphere, Pure Appl. Geophys., 118, 284-306, doi:10.1007/BF01586455.

Kinnison, D. E., et al. (2007), Sensitivity of chemical tracers to meteorological parameters in the MOZART-3 chemical transport model, J. Geophys. Res., 112, D20302, doi:10.1029/2006JD007879.

Lott, F., and M. J. Miller (1997), A new subgrid-scale orographic drag parameterization: Its formulation and testing, $Q$. J. R. Meteorol. Soc., 123, 101-127, doi:10.1002/qj.49712353704.

Manzini, E., M. A. Giorgetta, M. Esch, L. Kornblueh, and E. Roeckner (2006), The influence of sea surface temperatures on the Northern winter stratosphere: Ensemble simulations with the MAECHAM5 model, J. Clim., 19, 3863-3881, doi:10.1175/JCLI3826.1.

Mayr, H. G., J. G. Mengel, C. O. Hines, K. L. Chan, N. F. Arnold, C. A. Reddy, and H. S. Porter (1997), The gravity wave Doppler spread theory applied in a numerical spectral model of the middle atmosphere: 2. Equatorial oscillations, J. Geophys. Res., 102(D22), 26,093-26,105, doi:10.1029/96JD03214.

Mengel, J. G., H. G. Mayr, K. L. Chan, C. O. Hines, C. A. Reddy, N. F. Arnold, and H. S. Porter (1995), Equatorial oscillations in the middle atmosphere generated by small scale gravity waves, Geophys. Res. Lett., 22, 3027-3030, doi:10.1029/95GL03059.

Pascoe, C. L., L. J. Gray, S. A. Crooks, M. N. Juckes, and M. P. Baldwin (2005), The quasi-biennial oscillation: Analysis using ERA-40 data, J. Geophys. Res., 110, D08105, doi:10.1029/2004JD004941.

Peña-Ortiz, C., P. Ribera, R. García-Herrera, M. A. Giorgetta, and R. R. García (2008), Forcing mechanism of the seasonally asymmetric quasibiennial oscillation secondary circulation in ERA-40 and MAECHAM5, J. Geophys. Res., 113, D16103, doi:10.1029/2007JD009288.

Ray, E. A., M. J. Alexander, and J. R. Holton (1998), An analysis of the structure and forcing of the equatorial semiannual oscillation in zonal wind, J. Geophys. Res., 103(D2), 1759-1774, doi:10.1029/97JD02679.
Reed, R. J. (1962), Some features of the annual temperature regime in the tropical stratosphere, Mon. Weather Rev., 90, 211-215, doi:10.1175/ 1520-0493(1962)090<0211:SFOTAT $>2.0 . \mathrm{CO} ; 2$

Roeckner, E., et al. (2003), The atmospheric general circulation model ECHAM5 - Part 1, Rep. 349, 127 pp., Max Planck Inst., Munich. Roeckner, E., R. Brokopf, M. Esch, M. Giorgetta, S. Hagemann, L. Kornblueh, E. Manzini, U. Schlese, and U. Schulzweida (2006), Sensitivity of simulated climate to horizontal and vertical resolution in the ECHAM5 atmosphere model, J. Clim., 19, 3771-3791, doi:10.1175/ JCLI3824.1.

Schmidt, H., G. P. Brasseur, M. Charron, E. Manzini, M. A. Giorgetta, T. Diehl, V. I. Fomichev, D. Kinnison, D. Marsh, and S. Walters (2006), The HAMMONIA chemistry climate model: Sensitivity of the mesopause region to the 11-year solar cycle and CO2 doubling, J. Clim., 19(16), 3903-3931, doi:10.1175/JCLI3829.1.

Schmidt, H., G. P. Brasseur, and M. A. Giorgetta (2010), Solar cycle signal in a general circulation and chemistry model with internally generated quasi-biennial oscillation, J. Geophys. Res., 115, D00I14, doi:10.1029/ 2009JD012542.

Vincent, R. A., S. Kovalam, D. C. Fritts, and J. R. Isler (1998), Long-term MF radar observations of solar tides in the low-latitude mesosphere: Interannual variability and comparisons with the GSWM, J. Geophys. Res., 103, 8667-3683, doi:10.1029/98JD00482.

Wallace, J. M. (1973), General circulation of the tropical lower stratosphere, Rev. Geophys., 11(2), 191-222, doi:10.1029/RG011i002p00191. Xu, J., A. K. Smith, H.-L. Liu, W. Yuan, Q. Wu, G. Jiang, M. G. Mlynczak, J. M. Russell III, and S. J. Franke (2009), Seasonal and quasi-biennial variations in the migrating diurnal tide observed by Thermosphere, Ionosphere, Mesosphere, Energetics and Dynamics (TIMED), J. Geophys. Res., 114, D13107, doi:10.1029/2008JD011298.

M. A. Giorgetta and H. Schmidt, Max Planck Institute for Meteorology, Hamburg, Germany.

M. Keller, Department of Physics, University of Toronto, Toronto, ON, Canada.

C. Peña-Ortiz, Universidad Pablo de Olavide, Departmento de Sistemas Físicos, Químicos y Naturales, Ctra. de Utrera, Km 1, E-41013 Sevilla, Spain. (cpenort@upo.es) 